Running Head: PSYCHOLOGIST'S VIEWS ON PEER REVIEW

Psychological researchers' views on peer review: a forward focused survey.

\author{
Brett Buttliere \\ Master Thesis \\ Supervisor: Jelte Wicherts \\ Tilburg University, Netherlands
}

Words: 8,832 
PSYCHOLOGIST'S VIEWS ON PEER REVIEW

\begin{abstract}
:
Despite much discussion concerning problems with, and potential changes to, the psychological publishing system, there has been little data gathered concerning psychologists' opinions about whether, or what, change needs to occur. Here we surveyed psychologists about: the literature in their subfield, the current publication system, the prevalence of problems in review, how helpful potential changes to the communication system might be, and their behavioral engagement in current change initiatives. While over half of psychologists agreed to being generally satisfied, most also agreed there is room to improve the communication system and indicated that several potential changes would be helpful. Unfortunately, the majority of psychologists also indicated not yet engaging behaviorally with current change initiatives. Sensible problem and change components were drawn from the data and were correlated to, for instance, how much trust the psychologist had in the literature of their subfield and how many papers they had published.
\end{abstract}

Keywords: Open science, Scientific communication, Survey, Change initiatives 
PSYCHOLOGIST'S VIEWS ON PEER REVIEW

Scientists have been pointing out problems and suggesting changes to the modern peer review system almost since it was widely adopted by the sciences in the late 1970's (Greenwald, 1975; Rosenthal, 1978; Rosenthal, 1979; Gottfredson, 1978; Benos et al., 2007). Unfortunately, these issues received little attention until several articles and data scandals in 2012 led to more attention and effort being put toward discussing the problems in the psychological publication system and designing solutions to those problems (Simmons, Nelson, \& Simonsohn, 2011; John, Loewenstein, \& Prelec, 2012; Levelt committee, 2012). Despite this widespread discussion, hardly any work (but see Fuchs, Jenny, \&Fiedler, 2012) has been done to discern what psychological scientists' think are the most pressing problems or the best potential solutions to those problems. The goal of the current survey was to help fill this gap by gathering and presenting data concerning psychologist's opinions on five major topics: the literature of their subfield, the current psychological review system, the prevalence of ten of the most cited problems in the current review system, how helpful fifteen of the most talked about potential changes to the system will be, and their behavioral engagement with ten change initiatives that have already been implemented.

\section{Problems in Psychology}

Recent papers have empirically demonstrated widespread 'Questionable research practices' (QRPs), low rates of replication, low rates of willingness to share data, and other selfcentred, rather than group-centred, behaviours in psychology (John, et al., 2012; Asendorpf et al., 2013; Rosenthal, 1979; Rosenthal, 1978; Wicherts, Borsboom, Kats, \& Molenaar, 2006). Given that just about anything can be made significant (Simmons, Nelson, \& Simonsohn, 2011), and that recent attempts to replicate high impact studies have failed (Doyen, Klein, Pichon, \& Cleeremans, 2012; Harris, Coburn, Rohrer, \& Pashler, 2013), some have begun to question how 
PSYCHOLOGIST'S VIEWS ON PEER REVIEW

many of the effects reported in the literature are legitimate (Ioannidis, 2005; Klein et al., 2014).

One reason flawed findings become published (no matter how many there are) is a less than perfect peer review system. Fifteen years ago Richard Smith (1999), then editor at the British Medical Journal, summarized the literature succinctly when he said, "Peer review is slow, expensive, profligate of academic time, highly subjective, prone to bias, easily abused, poor at detecting gross defects, and almost useless for detecting fraud" (p. 1). Recent demonstrations of an inability for review committees to detect fraud or accurately judge the quality of the paper bear this statement out empirically, with fake papers being allowed into the literature and Nobel prize winning papers initially being rejected (Levelt committee, 2012; Bohannon, 2013; Verfaellie, \& McGwin, 2011; Howard \& Wilkensen, 1998; Bornmann, 20121; Gans, \& Shepard, 1994; Campanario, 1995; Hojat, Gonnella, \& Caelleigh, 2003). Research has also empirically demonstrated the inefficiencies of review outlined by Smith (1999). For instance, Elsevier made over 1.1 billion dollars profit in 2010 while slowing science by hundreds of thousands of hours per year as articles sit on reviewers' desks in the submission, review, rejection, resubmission process (Edlin, \& Rubinfeld, 2004; Duranceau, 2014; Peters \& Ceci, 1982; Nosek, \& Bar-Anan, 2012). Indeed, research estimates that at least cost efficiency could be improved using suggested changes, which we speak on next (Houghton, \& Oppenheim, 2010).

\section{Potential changes}

Along with discussion of the problems in the current psychological communication system have come a large number of proposals to fix these issues. In this survey we ask psychologists their opinions concerning 15 of the most discussed proposals in an attempt to discern which the psychological community feels will be most helpful.

Perhaps one of the loudest calls thus far has been to open the peer review system. This 
PSYCHOLOGIST'S VIEWS ON PEER REVIEW

might come in the form of putting reviewer's names on the final paper, publishing reviews, or establishing a post-publication review system and is the direction that the biomedical sciences have taken in response to similar problems (Smith, 1999; Wicherts, Kievit, Bakker, \& Borsboom, 2012; Rennie, 1999; Nosek, \& Bar-Anan, 2012; Sxkolar, 2012). Empirical work on this topic has found that biomedical reviewers are willing to put their names on reviews and that signing reviews leads to no significant loss, or even an increase, in the quality of reviews (Pulverer, 2010; Godlee, Gale, \& Martyn, 1998; Van Rooyen, Godlee, Evans, Black, \& Smith, 1999; Walsh, Rooney, Appleby, \& Wilkinson, 2000). Others have suggested changing the review system in different ways, for instance, by training reviewers or adding statistical or methodological experts to review panels, with data suggesting that these additions lead to better papers (Gottfredson, 1978; Kovera, \& McAuliff, 2000; Cobo et al., 2007). Another suggestion has been to support the establishment of an appeals system at journals and better logs of unfair or inadequate reviews (Ho, Mak, Tao, Lu, Dap, \& Pan, 2013).

Other change initiatives have aimed to influence the behavior of researchers directly. There have been calls to avoid the file drawer problem or to conduct more studies that are confirmatory and pre-registered (Rosenthal, 1979; Asendorpf et al., 2013; Wagenmakers et al., 2012; Open Science Collaboration, 2012). Some have asked that authors report better, with some studies suggesting that checklists are an effective way to achieve this (Eich, 2014; Simmons et al., 2012; Mulligan, Hall, \& Raphael, 2012; Moher et al., 1999). Others have spotted that these behaviors were not engaged in the first place because they lowered the researcher's outcomes and have stressed the need to change the incentive system in order to facilitate these desired behaviors, with several different types of incentives have been built (Priem, Taraborelli, Groth, \& Neylon, 2010; Nosek et al., 2012; Hauser, \& Fehr, 2007). Another way to change the incentive 
PSYCHOLOGIST'S VIEWS ON PEER REVIEW

system is to increase the cost or risk of doing the antisocial behavior, and several tools have been developed which make it easier to detect less than perfect science (Francis, 2014; Simonsohn, Nelson, \& Simmons, 2013; Bakker \& Wicherts, 2011).

As many of these proposed solutions have been funded and developed already, we will also examine whether psychologists are engaging with these already implemented change initiatives. This is excellent, but too many options makes norms unclear, divides the marketing, lowering utility, and perhaps even hinders engagement (Buttliere, under review; Iyengar, \& Lepper, 2000). Unfortunately, there has been relatively little data collected given the amount of time and money put into these initiatives, especially in psychology; we review these works next.

\section{Surveys of scientists}

Two large, relatively similar, studies across science have found a general approval of the peer review system, though lamentations about time and problems with review (Ware \& Monkman, 2008; Mulligan et al., 2012). For instance, these surveys found that $65 \%$ and $69 \%$ of researchers approved of the double blind peer-review system, but also that only $32 \%$ and $36 \%$ of researchers agreed that the current publication system is the best science can achieve and that $32 \%$ and $30 \%$ of researchers agreed that the system needs a complete overhaul (Ware \& Monkman, 2008; Mulligan et al., 2012). Harley, Acord, Earl-Novell, Lawrence, and King (2010) conducted a series of focus groups in different fields about scientific communication practices and also found that, 'Not surprisingly, there was a fair amount of criticism about the editorial and peer-review process for both journals and books, including laments of long lag times and editorial quality issues.' (p. 13). Unfortunately, these surveys did not include psychologists, and we will examine these attitudes to those among psychologists. 
PSYCHOLOGIST'S VIEWS ON PEER REVIEW

Ho, Mak, Tao, Lu, Dap, and Pan, (2013) did a more specific study of whether biomedical researchers consider peer review to be fair, scientific, and transparent. They found somewhat surprising results in that less than half of their participants believed the peer review system to be scientific (48\%), fair (48\%), or transparent (25\%; Ho, et al., 2013). These researchers also found that $22 \%$ of Biomedical authors did not believe that reviewers were competent in general, that $11 \%$ said reviewers frequently imposed unnecessary references on a paper, and that $67 \%$ of biomedical researchers supported the installation of appeal systems at journals, in order to combat unfair reviews. We will compare these results with those among psychologists.

To our knowledge, there is only one published study of psychologist's opinions on the peer review system and potential changes (Fuchs, Jenny, \& Fiedler, 2012). Unfortunately, these authors asked only about Simmons et al.'s, (2012) suggestions for authors and reviewers and did not employ a systematic sampling technique. Additionally, over $50 \%$ of the individuals who started Fuchs et al.'s (2012) study exited before completing it, which leaves questions about the validity of the results. Here we will assess support for a greater number of potential changes and employ a randomly invited sample.

\section{The current survey}

With all the time and effort being put into improving the peer review system, especially in psychology, it seems time to gather data on the situation. To this end, we built a 50 item survey designed to gather data concerning psychologist's perceptions of five major topics: the trust psychologists have in their literature, how well they rate the current publication system, the most prevalent problems in review, the most helpful potential changes to the psychological communication system, and their engagement with current change initiatives. All materials for the survey can be seen at osf.io/zcv7e. After the email invitation and gaining consent, 
PSYCHOLOGIST'S VIEWS ON PEER REVIEW

participants were asked demographic questions including the number of publications they have in total (Mulligan et al., 2012), the number of publications they have reviewed in the past year, and their main subfield of research within psychology.

The first page of substantive content measured the participant's trust in the system by asking them to agree or disagree on a five point scale with the following four statements: "The research literature in my field is generally trustworthy," "I have confidence in the scientific progress of my field," "I often have doubts about the reproducibility and replicability of published findings in my field," and "Questionable research practices are a pervasive problem in my field."

The participant's opinions of the review process specifically were measured by asking the participant to agree or disagree (5 pt. scale) with the following eight statements: "There is room for improvement in the peer review process," "I am generally satisfied with the peer review system” (used earlier by: Mulligan et al., 2012; Ware \& Monkman, 2012; Ho et al., 2013), “ Reviewers are competent in general" (from Ho et al., 2013), "Journal peer review is scientific" (from Ho et al., 2013), "Journal peer review is fair" (from Ho et al., 2013), “Journal peer review is transparent" (from Ho et al., 2013), "Peer review is holding back scientific communication" (from Ware \& Monkman, 2008), “The current peer review system is the best we can achieve” (from Ware \& Monkman, 2008). The reuse of these questions allows us compare perceptions across fields.

The next section focused on the ten most discussed and cited problems with the current peer review system, specifically asking participants how often (never to very frequently) they felt the following ten problems occur: "A paper takes more than 6 months to review/ publish" (from Ho et al., 2013), “An individual reviews a paper without understanding the statistical analyses, 
PSYCHOLOGIST'S VIEWS ON PEER REVIEW

"Papers get more easily accepted because the authors are close colleagues of the editors and/or reviewers," "Papers get rejected because the editors or reviewers are working from competing theoretical frameworks," "Papers are assessed more critically because the authors are from a low-ranked university" (from Mulligan et al., 2012), "Junior researchers withhold criticisms of senior researcher"s work for fear of backlash," "Papers get more easily accepted because it is coauthored by a leader in the field," "An individual reviews a paper without sufficient knowledge of the topic," "Reviewers impose (their own) reviews on papers" (variations used by: Ho et al., 2013; Resnik, Guiterrez-Ford, \& Paddada, 2008), and "Reviewers use the articles information for their own benefit after rejection" (similar to Ho et al., 2013). At the end of these questions, participants were allowed a space where they could let us know about any problems that they felt we had overlooked.

After asking about the problems the psychologist perceives, we asked them to rate a series of potential changes for how probable they are to help the situation (definitely not helpful to definitely helpful). Participants were asked about the following 15 possible changes, in this order: "formally training reviewers" (from Mulligan et al., 2012), “establishing an appeals system at journals” (from Ho et al., 2013), “publishing peer-review reports alongside papers (open peer-review)," "always having a statistical expert involved in peer review," "incentivizing good reviews," "having reviewers become more tolerant of imperfections in the results" (from Fuchs et al., 2012), "lowering competition for journal space," "single-blind peer review (where the authors' names are known to the reviewer but the reviewers' names are not known to the author)" (similar to: Mulligan et al., 2012; Ware, \& Monkman, 2008), “double-blind peer review (where neither the author nor the reviewers are known to the other)" (similar to: Mulligan et al., 2012; Ware, \& Monkman, 2008), "including disclosure checklists concerning the reporting of 
PSYCHOLOGIST'S VIEWS ON PEER REVIEW

additional measures, manipulations, power analyses, and exclusions," "having peer-reviewers focus more on the theoretical/methodological quality of papers than on the novelty of the presented results," "journal publishers should routinely screen for potential misconduct (fabrication, falsification, plagiarism)," "supplementing review with post-publication review (where online readers can comment on and/or rate papers after publication)" (similar to: Mulligan et al., 2012; Ware \& Monkman, 2008), "signing peer reviews," "supplementing (or replacing) traditional citation metrics (e.g. H-index) with information about downloads of the paper, shares on social media, etc.” Participants were again allowed to indicate any important potential changes they were not asked about.

The final substantive portion of our survey asked participants about their behavioral engagement with ten change initiatives that have been implemented already. To our knowledge, this survey is among the first research to gather data of this sort. Specifically, the participant was asked to indicate how often (never to always) they engage in the following behaviors: "upload my data to an online data repository," "do secondary analyses on someone else's data," "make effort to use academic social media websites (e.g., academia.edu, openscienceframework.org) and open science tools," "publish replication studies," "publish in open access journals," "sign my work up for alternative impact metrics other than the H-index," "conduct replication studies," "pre-register studies," "write up studies if they fail," and "maintain a lab notebook." The next page thanked the participant for their participation and asked if they had any final comments; the final page of the survey provided a link where participants could provide their email to receive results, they were thanked again, then the survey was ended, 457 psychologists (20\%) provided their emails. 
PSYCHOLOGIST'S VIEWS ON PEER REVIEW

\section{Hypotheses}

Though the main goal of the survey was to 'let the data speak,' we did have several general hypotheses. Generally speaking, we hypothesized that the questions would lend themselves to principal component analyses, revealing underlying opinions/ constructs about problems and potential changes to the publication system, which could then be correlated to better understand how these attitudes relate to one another. We expected these component scores to show meaningful correlations, such that individuals who rated the system highly would perceive fewer problems with the system, believe suggested changes would help less, and be less likely to engage in with change initiatives. We also hypothesized that those who put more into the system (e.g., publications, reviews) would trust it more, perceive less bias, be less open to change, and engage with change initiatives less (i.e., people like things they 'built'; Norton, Mochon, \& Ariely, 2011). We also expected reasonable relations between the problems the individual perceives and the changes they endorse. For instance, we expected that those who see much bias in the system to be more positive about solutions that open the system (as this makes bias harder to conceal).

\section{Sample}

With these aims and hypotheses in mind, we designed our sample to include high quality, active, researchers. As such, in early November 2013, we queried Thompson Reuters Web of Science for all English articles published in 2013 under the subject heading of 'Psychology' and ended up with 23,395 entries. Duplicate corresponding authors $(3,038)$ were removed, each entry was assigned a random number, ordered, and the first 10,000 corresponding authors were contacted in small batches. 
PSYCHOLOGIST'S VIEWS ON PEER REVIEW

\section{Data collection}

Survey distribution utilized the Qualtrics mailer and took place between the $19^{\text {th }}$ of November and $2^{\text {nd }}$ of December, 2013; data collection stopped January $1^{\text {st }} 2014$. Approximately one week after the participants were first contacted with a request to fill in the survey, a reminder email was sent. After clicking through the link in an introductory email (can be read at osf.io/nf5tx) the participant saw a page containing the consent form, which mentioned the purpose of the survey, "to assess researchers' views on the scientific publishing system in psychology", and to "elicit views of potential improvements to the system." The participant was also told the average time to complete the survey (about 7 minutes), that the data would, "be confidential and aggregated at the presentation of results," and that their "participation is completely voluntary." Participants were also informed of how to get in touch with the researchers in case they had any further questions or concerns. After the information page, participants were conducted through the survey as discussed above.

\section{Results}

Of the 10,000 survey invitations sent, 9,733 were successfully delivered, 2,555 surveys were started and 2,304 finished completely. In order to assess non-random missingness for the participants who decided to end early, we compared the scores of those who left before completion against those who did not, examining, for instance, whether the groups differed in number of publications or reviews. Those who quit early $(\mathrm{N}=252)$ did have slightly less publications $(M=3.83, S D=1.59)$ than those who stayed in the survey $(M=4.13, S D=1.55$; $T(1,2485)=6.30, p=.01)$, but the grand mean (4.11) changes very little if we keep or correct for their missing values. Those who left early also had done fewer reviews in the last year $(M=$ $2.58, S D=1.18)$ than those who did not $(M=2.80, S D=1.19 ; T(1,2485)=-2.38, p=.02)$, but 
PSYCHOLOGIST'S VIEWS ON PEER REVIEW

again the grand mean (2.79) does not change according to whether we keep them in or not.

While these results suggest that less published individuals were more likely to leave, the results also suggest that the small number of people who left (10\%) could not drastically change the results, while opening up the researcher degrees of freedom many fold. For these reasons we move forward with list wise deletion, which is also the norm for studies of this type (Fuchs et al., 2012; Mulligan; 2012).

Removing participants who quit at different stages and two individuals who had not published any papers, 2,302 complete surveys remained, representing a $23 \%$ full response ${ }^{1}$. While a $23 \%$ response rate is perhaps low in an overall sense, this number is quite high for internet surveys of researchers. The limit appears to be about 25\% with John et al. (2012) achieving $24 \%$ full response and some rates as low as $4 \%, 4.8 \%, 7.7 \%$ or $10 \%$ (Rowlands, Nicholas \& Huntingdon 2004; Ho et al., 2013; Ware, \& Monkman, 2008; Mulligan et al., 2012). The average participant in the sample has between 11 and 15 publications, and reviewed between 1 and 5 times in the last year. There was a .59 correlation between the number of publications and the number of reviews an individual does. The top three subfields sampled were Cognitive: 376, Social: 373, and Clinical Psychology: 344; the smallest group was Forensic Psychology, with 52 respondents. The 'Other' category was utilized 247 times by individuals from such fields as Education, Sociology, Psychiatry, and Psychoanalysis; these individuals are grouped as one in the analyses. Though not our main focus, there were significant differences across fields in the number of publications $F(10,2291)=3.68, p=.001$, such that Neuroscience $(M=4.41, S D=$ $1.65)$ and Health psychologists $(M=4.38, S D=1.67)$ had the most publications (between 11 and $25)$ and Social $(M=3.85, S D=1.43)$ and Industrial Organizational (i/o) psychologists $(M=3.86$,

\footnotetext{
${ }^{1}$ It is unknown how people without any publications took part in the survey, as our sample was exclusively corresponding authors from papers published between January 1, 2013 and November 14, 2013. Our best guess is that the survey was passed on somewhere, though it is possible that these are mistakes or that these individuals were intentionally providing bad information.
} 
PSYCHOLOGIST'S VIEWS ON PEER REVIEW

$S D=1.41$ ) had the least publications (between 6 and 10). There were no significant differences in number of reviews $F(10,2291)=1.52, \mathrm{p}=.13$.

\section{General trust in the literature}

Results from this sample suggest that there was a general trust in the work being produced by psychologists, though about one in three indicated doubting reproducibility (cf. Table 1 \& Figure 1). For instance, over $80 \%$ of respondents agreed with the statements, "The research in my field is generally trustworthy" and "I have confidence in the scientific progress of my field" (Figure 1). At the same time, 32\% of researchers agreed that they, "often have doubts about the reproducibility and replicability of published findings in [their] field" and 16\% agreed that "Questionable research practices are a pervasive problem in my field." As we expected, these four questions formed one cohesive principal component substantively focusing on the individual's trust in the published findings of their subfield. Trust and confidence loaded above .78 while Doubt and QRPs both loaded greater than |-.73| (loadings can be seen in Table 1); this component explained $60 \%$ of the variance and explanatory power was not appreciably improved by adding another component.

\section{General opinions of the psychological review system}

Responses indicated the majority of psychologists are relatively satisfied with the peer review system, but also that there was a widespread recognition that things can improve (cf. Figure $2 \&$ Table 2). For instance, more than half (54\%) of psychologists reported being generally satisfied, but this number is low compared with Ware and Monkman (2008), who estimated 64\% satisfaction and Mulligan et al. (2012), who estimated 69\% general satisfaction with the system across many fields (with about $2 \%$ error of estimation in all studies). Not only were psychologists less satisfied generally, they also didn't rate the current system as highly, 
PSYCHOLOGIST'S VIEWS ON PEER REVIEW

with only $15 \%$ of psychologists agreed that this publication system is the best we can achieve.

This was, again, lower than previous estimates of $32 \%$ and $36 \%$ agreement with the same statement (Mulligan et al., 2012; Ware \& Monkman, 2008). The most forceful statistic concerning these questions was the $84 \%$ agreement with the statement, "There is room for improvement in the peer review process." On the other side of the issue, the number of psychologists who said that "Peer review is holding back scientific communication" has not grown, with agreement of about 17\% which was similar to Ware and Monkman's (2008) 19\% estimation across several fields.

Despite the apparently lower satisfaction with the publication system in psychology compared to science overall, the current psychological review system performed slightly better than the current biomedical review system on measures of how scientific and transparent it is perceived to be. Just over half $(58 \%)$ of the surveyed psychologists agreed that the peer review system is scientific, compared to the $48 \%$ agreement found by Ho et al. (2013). Additionally, $30 \%$ of psychologists agreed the peer review system is transparent, compared to approximately $25 \%$ of biomedical researchers and $46 \%$ of psychologists agreed that the review system is fair, just below their $48 \%$ estimated agreement (Ho et al., 2013). A scree plot indicates that these questions load on one principal component (explaining $43 \%$ of the variance), reflecting the individual's rating of the review system, as can be seen in Table 2, all eight questions loaded well on one principal component (above |.54|).

\section{Perceived problems with the peer review system.}

The results from questions about perceived problems in the review system reveal that most psychologists perceive most problems to happen sometimes. The three most prevalent problems concerning peer review in the community's eyes were: reviews taking more than 6 
PSYCHOLOGIST'S VIEWS ON PEER REVIEW

months, field leaders having an easier time getting things published, and reviewers lacking statistical knowledge (cf. Figure $3 \&$ Table 3). The three least prevalent problems according to this sample were: breaches of confidentiality, junior scholars withholding criticisms of senior's work, and bias against low-ranked universities. Only these three problems are have means below the midpoint of the scale (sometimes), which indicates the large number of psychologists who feel these problems Frequently occur.

While psychological peer review was rated as more scientific and transparent than biomedical review, it appears to be among the slowest in science. Nearly three quarters (74\%) of psychologists indicated that reviews frequently take longer than six months while Ho et al.

(2013) found that only $11 \%$ of biomedical researchers said the same, while Ware and Monkman (2008) estimated the average review time at about 2.5 months (80 days), and Mulligan (2012) found that only $31 \%$ of all reviews were estimated to take longer than 6 months. The results also suggest that psychological reviewers are also more likely to impose (their own) references on a paper, as nearly a quarter $(24 \%)$ of psychologists indicated that reviewers frequently impose (their own) references on a paper, which is similar to Resnik, Guiterrez-Ford, and Paddada's (2008) $22.4 \%$ estimation of researchers ever experiencing the imposition of a reference, but much higher than Ho et al.'s (2013) 7\% percent indication that unnecessary references were frequently imposed in biomedical review. Luckily, only $4 \%$ of psychologists indicated that breaches of confidentiality frequently occur; which is quite similar to Ho et al.'s (2013) $2 \%$ estimated agreement to this question. Moreover, only $22 \%$ of our participants said that authors from low ranked universities frequently have a harder time publishing a paper; compared to Mulligan's (2012) 32\% agreement that researchers from developing countries have a harder getting published (compare this to our questions on fairness, where we perceived review as less 
PSYCHOLOGIST'S VIEWS ON PEER REVIEW

fair than biomedical researchers). Whether psychological review is actually easier on authors from developing countries compared to other fields or whether this is only perceptions of the liberal and inequality conscious social psychologists is currently unknown.

More than $50 \%$ of the psychologists surveyed used the neutral sometimes option on four of the ten problems we asked about, all of which were questions framed such that the wrong was due to a particular other person (compared to the field or system). These questions were: reviewer lacks theoretical understanding (64\%), reviewer lacks statistical understanding (55\%), reviewer imposes (own) references (53\%), and editors or reviewers rejecting a paper because it is from a competing theory (52\%). Forty-eight percent used the neutral sometimes option for how often nepotistic author-editor relationships occur and $45 \%$ used sometimes when indicating the frequency of junior reviewers withholding criticism on a senior's work. These problems are perceived to be relatively common anyways (lacking theory is fifth, lacking statistics is third), but results suggest that psychologists may be inhibiting their responses when the question is framed in terms of a specific other psychologist doing a wrong.

The scree plot and principal component analysis highlighted two principal components which we extracted using Oblimin rotation, allowing for correlations between the components (Tabachnik \& Fidell, 2001). The first principal component concerned perceptions about the frequency of Biased reviews, the four highest loading questions were: bias against low-ranked universities (.81), big name bias (.78), junior reviewers withholding criticisms (.73), and nepotistic author-editor relationships (.67). The second component concerned the prelevance of Bad (or inadequate) reviews, generally speaking, as the four highest loading questions were: an individual reviews a paper without statistical understanding (.79), an individual reviews a paper 
PSYCHOLOGIST'S VIEWS ON PEER REVIEW

without theoretical understanding (.78), a reviewer imposes (their own) references (.64), and reviews taking six months (.40). These two factors were correlated at $.38(n=2,302)$.

\section{Potential solutions}

When examining psychologists' perceptions of potential changes to the system, it appears that most psychologists endorsed several potential change initiatives, but without a consensus concerning what to do next (cf. Figure $4 \&$ Table 4 ). Nine of the fifteen solutions had over $40 \%$ of psychologists suggest it would be probably or definitely helpful in improving the situation, while the double blind review (the most popular course of action) had $64 \%$ of psychologists indicate it would be probably or definitely helpful. Support for the double blind review seems to be down almost 10\% from Ware and Monkman (71\%; 2008) and Mulligan et al.'s (76\%; 2012) estimates. The three highest rated potential changes, on average (not counting double-blind review) were: journals screening more for QRPs $(M=3.72,61 \%$ supported this solution), incentivizing good reviews $(M=3.57,58 \%$ supported), and including a statistical expert on each review ( $M=3.44,50 \%$ supported), though again, approximately two-thirds of the solutions had above $40 \%$ of psychologists suggest it would be probably or definitely helpful in improving the situation (Table 4), indicating that there is no clear consensus about what to do.

While other fields have decided that the best course of action was to open review (e.g., biomedical sciences), the overall three lowest rated potential changes to the review system all concerned opening review: single blind review $M=1.92,7 \%$ supported $)$, signing reviews $(M=$ $2.72,26 \%$ supported) and publishing reviews $(M=2.86,29 \%$ supported $)$. These results are similar to Mulligan et al., (2012), who found that 25\% of their sample agreed that signing reviews would probably improve the situation. The addition of post publication review seemed to maintain its share of support (38\% indicated probably helpful) but it was still only the $10^{\text {th }}$ 
PSYCHOLOGIST'S VIEWS ON PEER REVIEW

most popular solution overall. This level of support is similar to Ware and Monkman's (2012)

$37 \%$ agreement and lower than Mulligan et al.'s (2008) 47\% agreement for post publication beet review . Overall, it appears that psychologists like blind review, with potentially the option to review post publication; there appears to be little support for opening review at present.

Almost half (47\%) of psychologists indicated training reviewers would probably or definitely be helpful, but this is lower than Mulligan's (2012) estimated 67\% support for training reviewers. Training reviewers was not the only potential solution to find less empirical support than previous surveys, Ho et al. (2013) found that $67 \%$ of biomedical researchers supported the establishment of appeals systems at journals, while only $40 \%$ of our participants endorsed this approach. Fuchs et al. (2012) found general (84\%) support among psychologists for tolerating imperfections, but only $43 \%$ of our sample indicated that tolerating imperfections would probably be helpful in improving the situation. This difference could be due to the changing focus of discussions over the last two years, or it may be a difference in the samples, as their sample was collected through list serves at a very heated moment in the discussion (Simmons, 2011; John et al., 2012).

The scree plot indicated four noteworthy components best explained the data, which were again extracted using Oblimin rotation. The first component pertained to Opening the review system, the top four loading potential changes were: publish reviews (.74), enhance review with post publication review (.74), sign reviews (.55), and establish appeals systems at journals (.54). The second component centered around Lowering competition to publish, the top three loading changes were: tolerate imperfections (.82), lower competition (.76), and focus more on quality rather than novelty (.65). The third component dealt with Strengthening review, the three highest loading potential changes were: include a statistical expert on review (.67), incentivize good 
PSYCHOLOGIST'S VIEWS ON PEER REVIEW

reviews (.66), and use more checklists in the submission process (.65). The fourth component that added predictive power was mostly Double blind (.76), but also had single blind (-.53), train reviewers (.46), and journals screening more for QRP's (.43). In total, these four components explained $49 \%$ of the total variation in the 15 potential changes put forward, which was not appreciably improved by adding another factor. The three components for change (e.g., Opening the review system, Lowering competition, Strengthening review) were correlated between .15 and $.24(n=2,302)$, though these were not correlated with the Double blind component.

\section{Current behavioral engagement}

The most noticeable thing about the questions concerning behavioral engagement with current initiatives is how low the means were (cf. Table $5 \&$ Figure 5). Over $50 \%$ of psychologists said they had never: signed their works up for alternative metrics (77\%), preregistered a study (75\%), uploaded their data to a repository (63\%), published open access (58\%), or published a replication study $(51 \%)$. Whether this was due to the novelty of these actions or because people simply don't feel like doing these actions is worth their time is currently unknown and an excellent avenue for future research (psychologists have been asking for more replication and better reporting since the late 1970's). These behaviors were simply not being performed, and one of the major points of emphasis in the coming years should be how to get individuals engaging in these behaviors. The low behavioral engagement overall being noted,

$46 \%$ of psychologists indicated they regularly use a lab notebook $(M=2.55), 25 \%$ indicated they regularly conduct replication studies $(M=2.13)$, and $20 \%$ said they regularly write-up failures $(M=1.95)$.

A scree plot suggested three major components, which were again extracted using principal component analyses with Oblimin rotation. The top three loading questions on the first 
PSYCHOLOGIST'S VIEWS ON PEER REVIEW

component, called Replications were: conducting replications (.86), publishing replications (.83), and writing up failed studies (.40). The second component was called Avoid the file drawer, the top three loading questions were: pre-registering studies (.75), uploading datasets (.67), and keeping a lab notebook (.51). The third and final component dealt with Using the internet and the top three loading questions were: sign up work for alternative metrics (.79), use academic social media websites (.73), and publish open access (.61). These three components were all positively correlated between .17 and $.29(n=2,302)$.

\section{Correlations of component scores}

We next examined the correlations between the components, the results of which can be seen in Table 6. Correlations above .05 are significant at the .01 level, though this does not necessarily mean these correlations are practically significant. Here we found evidence for our first major hypothesis; that those who have more trust in the work, like the system better, saw fewer problems in review, were less open to potential changes, and were less likely to engage in current initiatives. First, there was a .39 correlation between the Trust the individual had in the work of the system and how well the individual Rated the peer review system. These Trust and Rating components were negatively related to perceived problems, albeit rather weakly ( $r$ 's between -.29 and -.47). Perceptions of problems in review were more strongly correlated with the individuals Rating of peer review (e.g., $r s=-.43 \&-.47$ ) than to Trust in the work of the field (e.g., $r \mathrm{~s}=-.29 \&-.29$ ), as problems with the system (e.g., Bias, Bad reviews) only indirectly affect the quality of the literature. Trust in the system was also negative correlated with a desire for change ( $r$ 's between -.14 and -.22), while endorsement of the traditional Double blind system was positively correlated (though weakly .09) with the Trust an individual had in the work of 
PSYCHOLOGIST'S VIEWS ON PEER REVIEW

their subfield. Individuals who trusted the system did report engaging slightly less with current initiatives, though the correlations were quite small and often not significant.

Our second hypothesis was that those with more publications and reviews (more successful under the current system), would trust the system more, be less likely to see problems, endorse change, or engage with initiatives (Norton, Mochon, \& Ariely, 2011). Support for this hypothesis was mixed (again, correlations above .05 are significant beyond .01). Publications and Reviews were correlated to each other at .6, and these variables were weakly positively correlated to Trust in the literature and the individual's Rating of the system ( $r$ s between .04 and .08). Those who had more publications and reviews were less likely to perceive Bias as a problem in the system ( $r$ s -.11 and -.12 respectively). Those with many publications were more reluctant to endorse change to the system ( $r$ s between -.11 to -.23), Opening review was the only potential solution that was more disliked by those with many reviews than those with many publications ( $r$ s -.14 \& -.12 respectively), presumably because Opening review makes reviewers jobs harder, whereas the other potential solutions make authors jobs harder. Unexpectedly, both frequent reviewers and frequent authors disliked the double blind review system more than their less published colleagues ( $r$ 's -.23 and -.18). The highly successful did report engaging more with initiatives, especially engaging in more Replication ( $r$ 's between.15 and .17).

There was also a tendency for the component scores to clump according to category. For instance, there was a .39 correlation between the amount of trust an individual had in the work of the system and their overall rating of the system. Similarly, the components related to perceptions of problems (Bias \& Bad reviews) were correlated at .38. Excepting the traditional double blind component, the potential solutions were correlated between .15 and .24 . Finally, the engagement components were correlated between .17 and .29. These correlations and factors 
PSYCHOLOGIST'S VIEWS ON PEER REVIEW

largely remained consistent if we submit the entire questionnaire to a principal component analysis (with Oblimin rotation); 4 major components emerged: one for the individual's trust in the system, one for the individual's rating of the system and perceived problems, one for potential solutions, and one for behavioral engagement.

There were also the general relationships one might expect. For instance, perceiving Bias in the system was positively correlated with a desire to Open the review system $(r=.28)$ and/ or Lower competition to publish $(r=.26)$, while being not as strongly correlated with Strengthen reviews $(r=.10)$ or maintaining the current system $(r=.06)$, presumably because these solutions do not solve the problem of bias. There was also a .23 correlation between wanting to open the peer review system and using the internet to open science, which is more clearly linked than lowering competition $(r=.04)$, strengthening reviews $(r=.10)$, or double blind review $(r=.02)$.

\section{Differences by person factors}

In order to better visualize what, exactly, these correlations mean, we next compare component scores by the person variables we collected (e.g., subfield, publications, reviews).

Originally, analyses of variances and regressions were run at the single item level, but the sample size made almost any difference in means significant, and more than half of the individual variables are significant for subfield, publications, and reviews. While we could describe only the questions with the largest differences, many of these effects were more efficiently described by examining differences on the factor scores. For instance, the individual double blind question had an $F$ value of 19.05 , while single blind had an $F$ value of 7.16 , but both were described by the double blind factor. Thus, we examined factor scores.

Component differences by field. Figure 6 displays differences in factor scores by subfield. Fields that have had recent data scandals (like Social and Neuroscience Psychology) 
PSYCHOLOGIST'S VIEWS ON PEER REVIEW

had less trust in their subfield $F(10,2291)=4.05, p<.001$, though fields did not differ in terms of their overall rating of the system $F(10,2291)=1.52, p=.12$. Personality and Neuroscience perceived more Bias in their review systems than Quantitative and Forensic psychology $F(10$, $2291)=4.73, p<.001$; subfields were equal in their perception of Bad reviews $F(10,2291)=$ $1.21, p=.28$ I/o psychologists particularly appreciated the Double blind system while neuroscience and cognitive psychologists relatively disliked it $F(10,2291)=15.07, p<.001$ while particularly social psychologists desired to Lower competition for publishing $F(10,2291)$ $=8.90, p<.001$. The fields also differed in which initiatives they engage with. Perhaps unsurprisingly, those from Health, Quantitative, Clinical and Neuro Psychology put more effort into Avoiding the file drawer (the NIH approach) than i/o and social psychologists $F(10,2291)$ $=8.31, p<.001$ while Neuroscience, Health, and Cognitive Psychologists utilized academic social media sites more $F(10,2291)=6.38, p<.001$. Fields were equal in their efforts to Replicate $F(10,2291)=1.39, p=.18$.

Component differences by publication. There were also interesting differences in opinion between those who have published many times and those who have not. Those with more publications rated the system more highly $F(5,2296)=3.67, p<.001$, perceived less bias $F(5,2296)=6.65, p<.001$, and endorsed every potential solution less than those with fewer publications (Figure 7). This is in accordance with our hypothesis that those who have been successful under the current system like it better and do not want to change it. Not in line with our hypotheses were the results suggesting that those who had many publications also liked the Double blind review system less $F(5,2296)=27.48, p<.001$, conducted and published more Replications $F(5,2296)=15.81, p<.001$, and put more effort toward Avoiding the file drawer $F(5,2296)=5.21, p<.001$ than those with fewer publications. These differences raise 
PSYCHOLOGIST'S VIEWS ON PEER REVIEW

important questions about who exactly should be leading the change, if authors of different seniority desire different change.

Component differences by number of reviews last year. Differences in opinion by number of reviews track rather closely differences by publications, as can be seen in Figure 8 . For instance, those with more reviews rated the system more highly $F(6,2296)=3.53, p<.001$ and perceived less biases in the review system $F(6,2296)=7.74, p<.001$. Those who did no reviews and those who did many perceived fewer instances of bad reviews $F(6,2296)=2.14, p$ $<.001$, perhaps because those who did many reviews are defending their own work, while those who did no reviews feel they have no right to judge, though this could be looked at more. Those with more reviews desired less to open the peer review system $F(6,2296)=11.38, p<.001$, which is an effect which is not present in the publication analyses. This makes sense though because it is the only one that would make reviewer's jobs harder. Those with many reviews also did not like double blind peer review either $F(6,2296)=15.77, p<.001$, and also conducted more replications $F(6,2296)=11.79, p<.001$. These results make sense, individuals who do more reviews think more highly of them in that they are less likely to perceive bias in their own work (Norton, Mochon, \& Ariely, 2011), and do not want to make their jobs harder by opening the review system.

\section{Discussion}

There has been much discussion about problems in and potential changes to the psychological publication system, though little data gathered on what change psychologists endorse, if any. Here we aimed to fill this gap by surveying psychologists' opinions about five major topics: (1) the literature in their subfield, (2) the current publication system, (3) the perceived prevalence of problems in peer review, (4) how helpful potential changes to the scientific communication system might be, and (5) engagement with current change initiatives. 
PSYCHOLOGIST'S VIEWS ON PEER REVIEW

To our knowledge, this is the first survey data that uses a randomly invited (compared to snowball, or listservs) sample examining what psychologists consider to be the most prevalent problems in the psychological publishing system, what changes (if any) they think will be helpful for the future of that system, and behavioral engagement with change initiatives that have already been implemented. We hope that these data can be utilized to help discern which problems are most important to solve, and help design better solutions to solve those problems.

The results of the survey suggest that psychologists generally trust the literature in their subfield, while also recognizing that the review process could be improved (Tables $1 \& 2$ ). For instance, over $80 \%$ of psychologists agreed that they trust the literature and progress of their subfield, while only $32 \%$ reported seriously doubting replicability and only $16 \%$ agreed that QRPs are pervasive. Fifty-four percent of the surveyed psychologists reported being generally satisfied, which is lower than previous estimations across many fields (Ware, \& Monkman, 2008; Mulligan et al., 2012), but only $20 \%$ of psychologists indicated active dissatisfaction and only $17 \%$ agreed that review is holding back scientific communication. This being said, $84 \%$ of psychologists agreed there is room to improve the peer review system and only $15 \%$ agreed that this review system is the best we can achieve. These questions generally loaded on two components representing Trust in the literature and Rating of the publication system, which were positively correlated at .39 .

One of the main goals of this survey was to gather data on what psychologists perceived to be the most prevalent problems in the review system. That papers take longer than six months to review, that papers get more easily accepted if coauthored by a leader in the field, and that reviewers do not understand the statistics of a paper were perceived to be the most prevalent problems in psychological review. The data also suggest that psychological review is one of the 
PSYCHOLOGIST'S VIEWS ON PEER REVIEW

slowest in science, as 74\% of psychologists indicated reviews frequently take longer than 6 months, compared with estimates of $30 \%$ across science and $11 \%$ in the Biomedical fields (Mulligan et al., 2012; Ho et al., 2013). Every problem but breach of confidentiality $(M=2.27)$ had more than half of psychologists indicate it happens at least sometimes (Table 3), suggesting that problems are quite common. The questions concerning problems in peer review were explained best by two factors generally labeled Biased reviews and Bad (inadequate) reviews, which were again positively correlated at .38 . As expected, the amount of trust an individual had in the system was negatively correlated with how many problems they perceived in the system.

The second central goal of the survey was to assess how helpful psychologists feel potential changes to the communication system might be. The results indicate that, according to the average psychologist, the best potential publication system is some sort of double blind review where journals screen more for QRPs, good reviews are incentivized, and a statistical expert is involved in each review. But, there was no strong consensus, as, aside from opening the review system and lowering competition to publish, every potential solution was thought to be probably or definitely helpful by about $40 \%$ of psychologists while the most popular solution, double blind, had about $64 \%$ approval (Table 4). As such, we conclude that there appears to be a motivation and optimism for change, but no clear consensus as to what to do next. On average, the three lowest potential changes all related to opening review (i.e., single blind review, sign peer review, publish review; Table 4); this was a surprise as opening review is how other fields have reacted to similar problems and it has received growing attention in psychology (Smith, 1999; Pulverer, 2010; Kriegeskorte, et al., 2012; Wicherts, et al., 2012). It is interesting to note though that of the four potential change components pulled from the data (e.g., Open review, Lower competition, Strengthen review, Double blind system), Opening review was the 
PSYCHOLOGIST'S VIEWS ON PEER REVIEW

component that explained the most variation (was the most polarizing) and it was positively correlated with the other attempts to change the review system above .2 , though not with the Double blind solution.

Thus, it appears that psychologists recognized things can be improved and endorsed change; unfortunately, there appeared to be relatively few psychologists actively engaging in change initiatives. In this sample, over $50 \%$ of psychologists indicated they had never: signed their work up for alternative metrics (77\%), pre-registered a study (75\%), uploaded their data to a repository $(63 \%)$, published open access $(58 \%)$, or published a replication study (51\%; Table 5). On the other hand though, $49 \%$ of our participants report publishing at least one replication study, and $46 \%$ of psychologists report regularly using a lab notebook. Given the high enthusiasm for change, but the low behavioral engagement, one of the largest challenges moving forward will be to understand why engagement is so low and how to raise it.

The novelty of the practices seems to be an important factor in why already implemented change initiatives are not being utilized and we suspect that engagement will increase as norms become established and the utility of the change initiatives is demonstrated. The lack of a strong consensus in what to do next (Table 4) might also be hindering behavioral engagement, as what solutions are worthy of investment is uncertain (Kahneman \& Tversky, 1979). Another possibility is that psychologists do not believe the current solutions will be helpful, instead leading to only more bureaucracy, which would also inhibit psychologists from engaging with that potential solution.

Ultimately, the most successful change initiatives will be those that are so powerful and easy to use, that so plainly demonstrate their utility, that scientists will pick them up on their own (e.g., the wheel, the microscope, the internet; Buttliere, under review; Legris et al., 2003). One 
PSYCHOLOGIST'S VIEWS ON PEER REVIEW

way to do this is to focus on demonstrating the utility of the change or technology for the individual and the group. For instance, data has been collected demonstrating that focusing on the quality of the science, instead of novelty, and training reviewers leads to better papers (Kovera, \& McAuliff, 2000; Cobo et al., 2007). Space limitations prohibit us from discussing in depth the many interesting comments that psychologists made throughout the survey (especially comments concerning potential solutions); all comments and data can be seen at osf.io/4dw8h.

\section{Limitations}

Perhaps the most important limitation of the present study was the lack of detail it was able to go into. This limitation is most apparent with the potential changes, as there was no mention of implementation plans and several participants mentioned they missed this aspect. There is always a trade-off between length and detail and we decided to gather as much information as possible while limiting ourselves to 50 questions. Another potential limitation was that there was not an 'I don't know' option or that the participant could not leave an item blank. We believe a forced choice method was merited as the topic is sensitive and many questions probably would have been unanswered. Though it appears to not have been that big of an issue as only $10 \%$ of the participants left the survey without completing it, with decreasing numbers leaving as the study became more sensitive (only 20 of 2,556 left on the last, most sensitive, page). A final limitation we will mention is the fact that only $23 \%$ of our participants responded to the invitation to participate. This leaves open questions about the representativeness of our sample, as it may be the case that those who are very busy, or think that the system is fine, were less likely to take the survey. This might have led to an overestimation of problems and desire for change. On the other hand, we did find that those who left early had published and reviewed less, suggesting that this may not be the case (those with fewer publications also liked 
PSYCHOLOGIST'S VIEWS ON PEER REVIEW

the system less and endorsed more change). Finally, a $23 \%$ full response rate is among the best response rates for this type of study.

\section{Conclusion}

Abraham Lincoln famously said that if he was given six hours to cut down a tree, he would spend the first four hours sharpening the axe, and this is the attitude that I think will best serve those individuals who wish to see change implemented in the psychological publication system. We hope that this research will help us sharpen our axe, by helping to more efficiently assign resources and stimulate more research on the topic, leading to even better decisions. In this initial survey, the data suggest that psychologists trust the literature in their subfield, while recognizing that things can get better, though without a consensus of what to do next and little engagement with current change initiatives. We conclude that future discussion should focus on what the largest problems are and how best to solve them, focusing on generating data demonstrating that proposed solutions lead to better outcomes for both the group and the individual psychologist. 
PSYCHOLOGIST'S VIEWS ON PEER REVIEW

$\underline{\text { References }}$

Asendorpf, J. B., Conner, M., De Fruyt, F., De Houwer, J., Denissen, J. J., Fiedler, K., ... \& Wicherts, J. M. (2013). Recommendations for increasing replicability in psychology. European Journal of Personality, 27(2), 108-119.

Bakker, M., \& Wicherts, J. M. (2011). The (mis) reporting of statistical results in psychology journals. Behavior Research Methods, 43(3), 666-678.

Benos, D. J., Bashari, E., Chaves, J. M., Gaggar, A., Kapoor, N., LaFrance, M., ... \& Zotov, A. (2007). The ups and downs of peer review. Advances in Physiology Education, 31(2), $145-152$.

Bentham, J., \& Mill, J. S. (2004). Utilitarianism and Other Essays. Penguin UK.

Bornmann, L. (2012). The Hawthorne effect in journal peer review. Scientometrics, 91(3), 857862.

Bohannon, J., (2013). Who is afraid of peer review? Science, 342, 60-65.

Buttliere, B., (Under review). How science, psychology, and social media can be used to improve the dissemination and evaluation of scientific work. Frontiers in Computational Neuroscience.

Buttliere, B., (2014). The other side of the similarity research standard. Presented at SPSP 2014.

Campanario, J. M. (2009). Rejecting and resisting Nobel class discoveries: Accounts by Nobel Laureates. Scientometrics, 81(2), 549-565.

Cobo, E., Selva-O'Callagham, A., Ribera, J. M., Cardellach, F., Dominguez, R., \& Vilardell, M. (2007). Statistical reviewers improve reporting in biomedical articles: A randomized trial. PLoS ONE, 2(3), e332.

Darley, J. M., \& Latane, B. (1968). Bystander intervention in emergencies: diffusion of responsibility. Journal of personality and social psychology, 8(4p1), 377. 
PSYCHOLOGIST'S VIEWS ON PEER REVIEW

Doyen, S., Klein, O., Pichon, C. L., \& Cleeremans, A. (2012). Behavioral priming: it's all in the mind, but whose mind? PloS ONE, 7(1), e29081.

Duranceau, E. F., (2014). Elsevier fact sheet. Accessed May 10, 2014:

http://libraries.mit.edu/scholarly/mit-open-access/open-access-at-mit/mit-open-accesspolicy/publishers-and-the-mit-faculty-open-access-policy/elsevier-fact-sheet/

Edlin, A. S., \& Rubinfeld, D. L. (2004). Exclusion or Efficient Pricing: The" Big Deal" Bundling of Academic Journals. Antitrust Law Journal.

Eich, E. (2014). Business Not as Usual. Psychological science, 25(1), 3-6.

Francis, G. (2014). The frequency of excess success for articles in Psychological Science. Psychonomic bulletin \& review, 1-8.

Fuchs, H. M., Jenny, M., \& Fiedler, S. (2012). Psychologists are open to change, yet wary of rules. Perspectives on Psychological Science, 7(6), 639-642.

Gans, J. S., \& Shepherd, G. B. (1994). How are the mighty fallen: Rejected classic articles by leading economists. The Journal of Economic Perspectives, 8(1) 165-179.

Giner-Sorolla, R. (2012). Will We March to Utopia, or Be Dragged There? Past Failures and Future Hopes for Publishing Our Science. Psychological Inquiry, 23(3), 263-266.

Godlee, F., Gale, C. R., \& Martyn, C. N. (1998). Effect on the quality of peer review of blinding reviewers and asking them to sign their reports: a randomized controlled trial. Jama, 280 (3), 237-240.

Gottfredson, S. D. (1978). Evaluating psychological research reports: Dimensions, reliability, and correlates of quality judgments. American Psychologist, 33(10), 920.

Greenwald, A. G. (1975). Consequences of prejudice against the null hypothesis. Psychological Bulletin, 82(1), 1. 
PSYCHOLOGIST'S VIEWS ON PEER REVIEW

Harley, D., Acord, S. K., Earl-Novell, S., Lawrence, S., \& King, C. J. (2010). Assessing the Future Landscape of Scholarly Communication: An Exploration of Faculty Values and Needs in Seven Disciplines. California: University of California Press.

Harris CR, Coburn N, Rohrer D, Pashler H (2013) Two Failures to Replicate High-PerformanceGoal Priming Effects. PLoS ONE 8(8): e72467. doi:10.1371/journal.pone.0072467

Hauser, M., \& Fehr, E. (2007). An incentive solution to the peer review problem. PLoS Biology, 5(4), e107.

Ho, R. C., Mak, K. K., Tao, R., Lu, Y., Day, J. R., \& Pan, F. (2013). Views on the peer review system of biomedical journals: an online survey of academics from high-ranking universities. BMC Medical Research Methodology, 13(1), 74.

Hojat, M., Gonnella, J. S., \& Caelleigh, A. S. (2003). Impartial judgment by the "gatekeepers" of science: Fallibility and accountability in the peer review process. Advances in Health Sciences Education, 8(1), 75-96.

Houghton, J. W., \& Oppenheim, C. (2010). The economic implications of alternative publishing models. Prometheus, 28(1), 41-54.

Howard, L., \& Wilkinson, G. (1998). Peer review and editorial decision-making. The British Journal of Psychiatry, 173(2), 110-113.

Ioannidis, J. P. (2005). Why most published research findings are false. PLoS Medicine, 2(8), 124.

Iyengar, S. S., \& Lepper, M. R. (2000). When choice is demotivating: Can one desire too much of a good thing? Journal of personality and social psychology, 79(6), 995. 
PSYCHOLOGIST'S VIEWS ON PEER REVIEW

John, L. K., Loewenstein, G., \& Prelec, D. (2012). Measuring the prevalence of questionable research practices with incentives for truth telling. Psychological Science, 23(5), 524532.

Kahneman, D., \& Tversky, A. (1979). Prospect theory: An analysis of decision under risk. Econometrica: Journal of the Econometric Society, 263-291.

Klein, R. A., Ratliff, K. A., Vianello, M., Adams Jr, R. B., Bahník, Š., Bernstein, M. J., ... \& Woodzicka, J. A. (2014). Investigating variation in replicability. Social Psychology, 45(3), 142-152.

Kovera, M. B., \& McAuliff, B. D. (2000). The effects of peer review and evidence quality on judge evaluations of psychological science: Are judges effective gatekeepers? Journal of Applied Psychology, 85(4), 574.

Kriegeskorte, N., Walther, A., \& Deca, D. (2012). An emerging consensus for open evaluation: 18 visions for the future of scientific publishing. Frontiers in Computational Neuroscience,6.

Legris, P. Ingham, J., Collerette, P., (2003). Why do people use information technology? A critical review of the technology acceptance model. Information and Management, 40, 191-204.

Levelt Committee, (2012). Flawed science: The fraudulent research practices of social psychologyist Diederik Stapel. https://www.commissielevelt.nl/

Moher, D., Cook, D. J., Eastwood, S., Olkin, I., Rennie, D., \& Stroup, D. F. (1999). Improving the quality of reports of meta-analyses of randomized controlled trials: the QUOROM statement. The Lancet, 354, 1896-1900. 
PSYCHOLOGIST'S VIEWS ON PEER REVIEW

Mulligan, A., Hall, L., \& Raphael, E. (2013). Peer review in a changing world: An international study measuring the attitudes of researchers. Journal of the American Society for Information Science and Technology, 64(1), 132-161.

Norton, M., Mochon, D., \& Ariely, D. (2011). The 'IKEA effect': When labor leads to love. Harvard Business School Marketing Unit Working Paper, (11-091).

Nosek, B. A., \& Bar-Anan, Y. (2012). Scientific utopia: I. Opening scientific communication. Psychological Inquiry, 23(3), 217-243.

Nosek, B. A., Spies, J. R., \& Motyl, M. (2012). Scientific utopia II. Restructuring incentives and practices to promote truth over publishability. Perspectives on Psychological Science, 7(6), 615-631.

Open Science Collaboration (2012). An open, large-scale, collaborative effort to estimate the reproducibility of psychological science. Perspectives on Psychological Science, 7, 657660.

Peters, D. P., \& Ceci, S. J. (1982). Peer-review practices of psychological journals: The fate of published articles, submitted again. Behavioral and Brain Sciences, 5(02), 187-195.

Priem, J., Taraborelli, D., Groth, P., \& Neylon, C. (2010). Altmetrics: A manifesto.

Pulverer, B. (2010). A transparent black box. The EMBO Journal, 29(23), 3891-3892.

Rennie, D. (1999). Editorial peer review: its development and rationale. Peer review in health sciences. London: BMJ Books, 3-13.

Resnik, D. B., Gutierrez-Ford, C., \& Peddada, S. (2008). Perceptions of ethical problems with scientific journal peer review: an exploratory study. Science and Engineering Ethics,14(3), 305-310. 
PSYCHOLOGIST'S VIEWS ON PEER REVIEW

Rosenthal, R. (1978). How often are our numbers wrong? American Psychologist, 33, 10051008. doi:10.1037/0003-066X.33.11.1005

Rosenthal, R. (1979). The file drawer problem and tolerance for null results. Psychological Bulletin, 86(3), 638.

Rowlands, I., Nicholas, D., Huntingdon, P., (2004). Scholarly communication in the digital environment: What do authors want? Center for Information Behavior.

Simmons, J. P., Nelson, L. D., \& Simonsohn, U. (2011). False-positive psychology undisclosed flexibility in data collection and analysis allows presenting anything as significant. Psychological Science, 22(11), 1359.

Simonsohn, U., Nelson, L. D., \& Simmons, J. P. (2013). P-curve: A key to the file-drawer. Journal of Experimental Psychology: General, 143(2), 534-547. doi:10.1037/a0033242

Skinner, B. F., \& Hayes, J. (1976). Walden two (pp. 18-20). New York: Macmillan.

Smith, R. (1999). Opening up BMJ peer review: a beginning that should lead to complete transparency. BMJ: British Medical Journal, 318(7175), 4.

Sxkolar, D., (2012). Social networking for academics and scholars. Website accessed, 28-3-14: http://infospace.ischool.syr.edu/2012/06/21/social-networking-for-academics-andscholars/

Tabachnick, B. G., \& Fidell, L. (2001). Using multivariate statistics. Boston: Allyn and Bacon.

Thaler, R. H., \& Sunstein, C. R. (2008). Nudge: Improving decisions about health, wealth, and happiness. Yale University Press.

Van Rooyen, S., Godlee, F., Evans, S., Smith, R., \& Black, N. (1999). Effect of blinding and unmasking on the quality of peer review. Journal of General Internal Medicine, 14(10), 622-624. 
PSYCHOLOGIST'S VIEWS ON PEER REVIEW

Verfaellie, M., \& McGwin, J., (2011). The case of Diederik Stapel. Psychological Science Agenda.

Walsh, E., Rooney, M., Appleby, L., \& Wilkinson, G. (2000). Open peer review: a randomized controlled trial. The British Journal of Psychiatry, 176(1), 47-51.

Walther, A., \& Van den Bosch, J. J. (2012). FOSE: a framework for open science evaluation. Frontiers in Computational Neuroscience, 6.

Ware, M., and M. Monkman, (2008). Peer review in scholarly journals: Perspective of the scholarly community, an international study.

Wicherts, J. M., Borsboom, D., Kats, J., \& Molenaar, D. (2006). The poor availability of psychological research data for reanalysis. American Psychologist, 61(7), 726.

Wicherts, J. M., Kievit, R. A., Bakker, M., \& Borsboom, D. (2012). Letting the daylight in: reviewing the reviewers and other ways to maximize transparency in science. Frontiers in Computational Neuroscience, 6 (20). 
PSYCHOLOGIST'S VIEWS ON PEER REVIEW

Table 1: Descriptive statistics and component loadings for Trust in the system $(\mathrm{N}=2,302)$.

\begin{tabular}{lccccccc}
\hline & & \multicolumn{2}{c}{$\begin{array}{c}\text { Strongly } \\
\text { disagree }\end{array}$} & \multicolumn{3}{c}{$\begin{array}{c}\text { Strongly } \\
\text { agree }\end{array}$} & \multicolumn{2}{c}{$\begin{array}{c}\text { Component } \\
\text { Loadings }\end{array}$} \\
& $\mathrm{M}(\mathrm{SD})$ & 1 & 2 & 3 & 4 & 5 & $1^{\text {st }}$ \\
\hline 1. Trust in literature & $3.94(0.67)$ & .00 & .03 & .13 & .68 & .15 & .82 \\
2. Confidence in progress & $3.91(0.74)$ & .01 & .05 & .14 & .63 & .17 & .78 \\
3. Doubt reproducibility & $2.95(1.01)$ & .04 & .35 & .28 & .26 & .06 & -.73 \\
4. QRPs pervasive & $2.48(0.98)$ & .13 & .45 & .25 & .13 & .03 & -.76 \\
\hline
\end{tabular}

Note: Participants were asked to agree with statements, as described in the survey section. All questions load on a single factor above |.73|. 
PSYCHOLOGIST'S VIEWS ON PEER REVIEW

Table 2: Descriptive and component loadings for questions on peer review $(\mathrm{N}=2,302)$.

\begin{tabular}{|c|c|c|c|c|c|c|c|}
\hline \multirow[b]{2}{*}{ Variable } & \multirow[b]{2}{*}{$\mathrm{M}(\mathrm{SD})$} & \multicolumn{2}{|c|}{$\begin{array}{l}\text { Strongly } \\
\text { disagree }\end{array}$} & \multirow{2}{*}{$\begin{array}{c}\% \\
\text { Neutral } \\
3\end{array}$} & \multicolumn{2}{|c|}{$\begin{array}{l}\text { Strongly } \\
\text { agree }\end{array}$} & \multirow[t]{2}{*}{$\begin{array}{r}\text { Component } \\
\text { loadings }\end{array}$} \\
\hline & & 1 & 2 & & 4 & 5 & \\
\hline Room to improve & $4.04(0.70)$ & .00 & .03 & .12 & .61 & .23 & -.58 \\
\hline Generally satisfied & $3.34(0.85)$ & .02 & .18 & .27 & .52 & .02 & .79 \\
\hline Reviewers competent & $3.59(0.72)$ & .00 & .09 & .25 & .62 & .04 & .64 \\
\hline Review is scientific & $3.49(0.86)$ & .02 & .13 & .28 & .51 & .07 & .63 \\
\hline Review is fair & $3.30(0.82)$ & .02 & .15 & .37 & .43 & .03 & .77 \\
\hline Review is transparent & $2.89(0.94)$ & .05 & .32 & .32 & .27 & .03 & .64 \\
\hline Review holds back & $2.49(0.95)$ & .12 & .45 & .26 & .15 & .02 & -.54 \\
\hline Best we can achieve & $2.51(0.91)$ & .12 & .42 & .32 & .14 & .01 & .63 \\
\hline
\end{tabular}

Note: Participants were asked to agree with statements, as described in the survey section. Questions in order asked to participant. Note that all but one of the means are above the midpoint of the scale. All questions load on a single factor above |.54|. 
PSYCHOLOGIST'S VIEWS ON PEER REVIEW

Table 3: Descriptive statistics and component loadings for problems in peer review $(\mathrm{N}=2,302)$.

\begin{tabular}{lrrrrrrrr}
\hline & & Never & \multicolumn{3}{c}{ Very } & \multicolumn{3}{c}{ Component } \\
Variable & $\mathrm{M}(\mathrm{SD})$ & 1 & 2 & 3 & 4 & 5 & $1^{\text {st }}$ & $2^{\text {nd }}$ \\
\hline Review takes longer 6 months & $4.04(0.89)$ & .01 & .04 & .21 & .38 & .36 & -.04 & .40 \\
Rev lacks statistical understanding & $3.28(0.77)$ & .01 & .11 & .55 & .26 & .07 & -.07 & .79 \\
Reviewer/ editor close colleague & $3.13(0.91)$ & .02 & .21 & .48 & .20 & .09 & .67 & .17 \\
Competing theory bias & $3.09(0.83)$ & .02 & .20 & .52 & .20 & .06 & .46 & .29 \\
Bias against low ranked university & $2.83(0.94)$ & .05 & .33 & .40 & .16 & .06 & .81 & -.09 \\
Jr. reviewers withhold criticism & $2.75(0.85)$ & .05 & .34 & .45 & .13 & .03 & .73 & -.04 \\
Field leader bias & $3.65(0.89)$ & .01 & .07 & .36 & .37 & .19 & .78 & -.02 \\
Rev lacks theoretical knowledge & $3.10(0.69)$ & .01 & .14 & .64 & .19 & .04 & .00 & .78 \\
Rev imposes (own) references & $3.04(0.80)$ & .01 & .22 & .53 & .19 & .05 & .13 & .64 \\
Breach of confidentiality & $2.27(0.69)$ & .10 & .57 & .30 & .03 & .01 & .34 & .26 \\
\hline
\end{tabular}

Note: Participants were asked, "How often do you think the following issues arise in your chosen subfield?" The scale was never, hardly ever, sometimes, frequently, very frequently. Questions in order asked to participant. For full question wording, see the materials section. The first component was mostly about biases, while the second dealt with lacking reviews. Review takes longer than 6 months, Competing theory bias, and Breach of confidentiality did not load highly on any factor. 
Table 4: Descriptive statistics and component loadings for potential changes $(\mathrm{N}=2,302)$.

\begin{tabular}{lrrrrrrrrr}
\hline & & \multicolumn{3}{c}{$\begin{array}{c}\text { Definitely } \\
\text { not }\end{array}$} & \multicolumn{3}{c}{ Definitely } & \multicolumn{3}{c}{ Component } \\
loadings \\
Variable & $\mathrm{M}(\mathrm{SD})$ & 1 & 2 & 3 & 4 & 5 & $1^{\text {st }}$ & $2^{\text {nd }}$ & $3^{\text {rd }}$ \\
\hline 1. Train reviewers & $3.37(0.97)$ & .02 & .17 & .34 & .35 & .12 & .24 & .04 & .17 \\
2. Establish appeals system & $3.23(0.97)$ & .03 & .21 & .37 & .30 & .10 & .54 & .13 & -.12 \\
3. Publish peer review & $2.86(1.08)$ & .09 & .31 & .31 & .21 & .08 & .74 & .00 & .09 \\
4. Include stats expert as rev & $3.44(1.07)$ & .03 & .17 & .30 & .32 & .18 & .09 & -.09 & .67 \\
5. Incentivize good reviews & $3.57(1.07)$ & .04 & .13 & .25 & .38 & .20 & -.01 & .09 & .66 \\
6. Tolerate imperfections & $3.20(1.19)$ & .08 & .24 & .25 & .26 & .17 & -.11 & .82 & .08 \\
7. Lower competition to pub. & $2.86(1.11)$ & .09 & .34 & .28 & .20 & .09 & .12 & .76 & -.10 \\
8. Single-blind review & $1.92(0.95)$ & .39 & .40 & .14 & .05 & .02 & -.02 & -.05 & .35 \\
9. Double-blind review & $3.74(1.12)$ & .03 & .13 & .20 & .33 & .31 & -.17 & .04 & .08 \\
10. Use more checklists & $3.37(0.93)$ & .02 & .14 & .39 & .33 & .11 & .03 & .21 & .65 \\
11. Focus on quality (PLoS) & $3.33(1.12)$ & .04 & .22 & .27 & .30 & .17 & .03 & .65 & .13 \\
12. Journals screen QRPs & $3.72(1.00)$ & .01 & .11 & .26 & .36 & .25 & .19 & -.09 & .36 \\
13. Post-publication review & $3.10(1.09)$ & .07 & .25 & .29 & .28 & .10 & .74 & -.06 & .08 \\
14. Signed peer reviews & $2.72(1.16)$ & .15 & .32 & .26 & .18 & .08 & .55 & .18 & -.07 \\
15. Supplement H-index & $2.96(1.06)$ & .08 & .26 & .37 & .21 & .09 & .39 & -.02 & .15 \\
\hline
\end{tabular}

Note: Participants were asked, "Would implementing the following recommendations be helpful to improving the peer-review system and science in your field?" Scale anchors were, definitely not, probably not, maybe, probably, definitely questions in order asked to participant. For full question wording, see the materials section. Only 5 questions fell below maybe helpful, the midpoint of the scale, yet none of the means were above four, probably helpful. The three highest rated changes were (not counting double-blind review): Journals screening more for QRPs, incentivizing good reviews, and including a statistical expert on each review. The three lowest rated possible changes (without single blind review) were: signing review, publishing reviews, and lowering competition for journal space. The first component dealt with opening review, the second dealt with lower competition, the third strengthening review. Component four had only two questions above .5 , these being .76 double-blind and -.53 single-blind. Note that Training reviewers, Journals screening QRPs and Supplement H-index did not load highly on any factor. 
PSYCHOLOGIST'S VIEWS ON PEER REVIEW

Table 5: Descriptive and factor loadings for engagement in change initiatives $(\mathrm{N}=2,302)$.

\begin{tabular}{lccccccccc}
\hline & & Never & \multicolumn{3}{c}{ Regularly } & \multicolumn{3}{c}{ Always } & \multicolumn{3}{c}{ Loadings } \\
Variable & $\mathrm{M}(\mathrm{SD})$ & 1 & 2 & 3 & 4 & 5 & $1^{\text {st }}$ & $2^{\text {nd }}$ & $3^{\text {rd }}$ \\
\hline 1. Upload data to repository & $1.56(0.92)$ & .63 & .25 & .06 & .03 & .02 & -.02 & .67 & .11 \\
2. Conduct secondary analyses & $1.93(1.01)$ & .41 & .39 & .09 & .11 & .01 & .14 & .37 & -.05 \\
3. Use academic social media & $1.91(1.09)$ & .46 & .31 & .11 & .09 & .03 & -.03 & .03 & .73 \\
4. Publish replications & $1.63(0.78)$ & .51 & .39 & .07 & .03 & .01 & .83 & .01 & .09 \\
5. Publish open access & $1.61(0.87)$ & .58 & .29 & .07 & .05 & .01 & .06 & .13 & .61 \\
6. Sign up for alt metrics & $1.33(0.72)$ & .77 & .17 & .04 & .02 & .01 & .03 & -.05 & .79 \\
7. Conduct replications & $2.13(0.95)$ & .24 & .50 & .15 & .09 & .02 & .86 & -.04 & -.03 \\
8. Pre-register studies & $1.43(0.90)$ & .75 & .15 & .05 & .03 & .03 & -.07 & .75 & .01 \\
9. Write up failed studies & $1.95(0.95)$ & .35 & .45 & .12 & .06 & .02 & .40 & .41 & -.14 \\
10. Use lab notebook & $2.55(1.37)$ & .29 & .25 & .22 & .10 & .14 & .07 & .51 & -.02 \\
\hline
\end{tabular}

Note: Participants were asked, "how often do you engage in the following behaviors in your research?" The scale was never, sometimes, regularly, often, \& always. Questions are in the order asked to participant, for full item wording, please see the survey section. The first principal component concerns Replications, the second Avoiding file drawer, and the third Using the internet. Conduct secondary analyses and write up failed studies dis not load highly. 
PSYCHOLOGIST'S VIEWS ON PEER REVIEW

Table 6: Correlations between principal component scores $(\mathrm{N}=2,302)$

\begin{tabular}{|c|c|c|c|c|c|c|c|c|c|c|c|c|c|}
\hline & 1. & 2. & 3. & 4. & 5. & 6. & 7. & 8. & 9. & 10. & 11. & 12. & 13. \\
\hline 1. Publications* & 1.00 & & & & & & & & & & & & \\
\hline 2. Reviews* & .60 & 1.00 & & & & & & & & & & & \\
\hline 3. Trust in work & .05 & .04 & 1.00 & & & & & & & & & & \\
\hline 4. System rating & .08 & .07 & .39 & 1.00 & & & & & & & & & \\
\hline 5. Bias in review & -.11 & -.12 & -.29 & -.43 & 1.00 & & & & & & & & \\
\hline 6. Bad reviews & -.01 & .01 & -.29 & -.47 & .38 & 1.00 & & & & & & & \\
\hline 7. Open review & -.12 & -.14 & -.22 & -.29 & .28 & .14 & 1.00 & & & & & & \\
\hline 8. Lower competition & -.11 & -.01 & -.14 & -.24 & .26 & .20 & .20 & 1.00 & & & & & \\
\hline 9. Stronger reviews & -.12 & -.03 & -.14 & -.04 & .10 & .11 & .24 & .15 & 1.00 & & & & \\
\hline 10. Double blind & -.23 & -.18 & .09 & .01 & .06 & .07 & .00 & .02 & .16 & 1.00 & & & \\
\hline 11. Replications & .17 & .15 & -.06 & -.03 & .04 & .05 & .03 & .08 & .02 & -.09 & 1.00 & & \\
\hline 12. Avoid file drawer & .07 & .06 & -.03 & .00 & .00 & .03 & .12 & -.04 & .09 & .01 & .22 & 1.00 & \\
\hline 13. Use the internet & .00 & .03 & -.07 & -.09 & .15 & .03 & .23 & .04 & .10 & .02 & .17 & .29 & 1.00 \\
\hline
\end{tabular}

Note: Here are the factors with their top three loading questions, in order of strength of association. ${ }^{*}$ indicates that the measure was a single question, and not a component score. ** indicates that the question loads negatively. 1. Publications* 2. Reviews*3. Trust in work: Trust in literature, Confidence in progress, QRPs pervasive**. 4. System rating: General satisfaction, Review is fair, Review is transparent. 5. Bias: Bias against low-ranked universities, Field leader easier published, Jr. reviewers withhold criticism of Sr. 6. Bad reviews: Revs lack statistical understanding, Revs lack theoretical understanding, Revs imposes (their own) references. 7. Open review: Publish peer review, Post-publication peer review, Sign peer reviews. 8. Lower competition: Tolerate imperfections, Lower competition to publish, Focus on quality. 9. Stronger reviews: Include stats expert, Incentivize good reviews, Use more checklists. 10. Double blind: Double blind, Single blind*, Train reviewers. 11. Replications: Conduct replications, Publish replications, Write up failures. 12. Avoid file drawer: Preregister studies, Upload data, Maintain lab notebook. 13. Use the internet: Sign up for alt metrics, Use academic social media, Publish open access. For the full question wording please the survey section. 
PSYCHOLOGIST'S VIEWS ON PEER REVIEW

Figures

Figure 1: Response distributions for questions concerning psychologists' trust in the work of their subfield, sorted by question means $(\mathrm{N}=2,302)$.

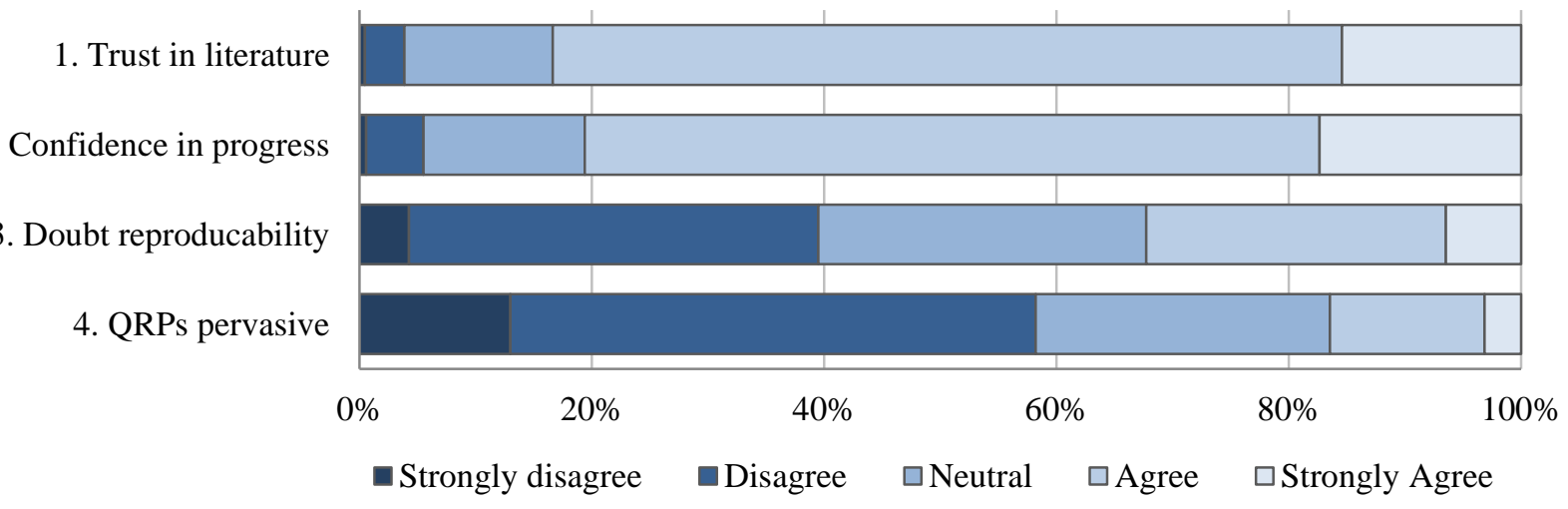


PSYCHOLOGIST'S VIEWS ON PEER REVIEW

Figure 2: Displayed are the response distributions for questions about peer review, sorted by question mean $(\mathrm{N}=2,303)$. Original question order in Table 2.

1. Room to improve

3. Reviewers competent

4. Review is scientific

2. Generally satisfied

5. Review is fair

6. Review is transparent

8. Best we can achieve

7. Review holds back
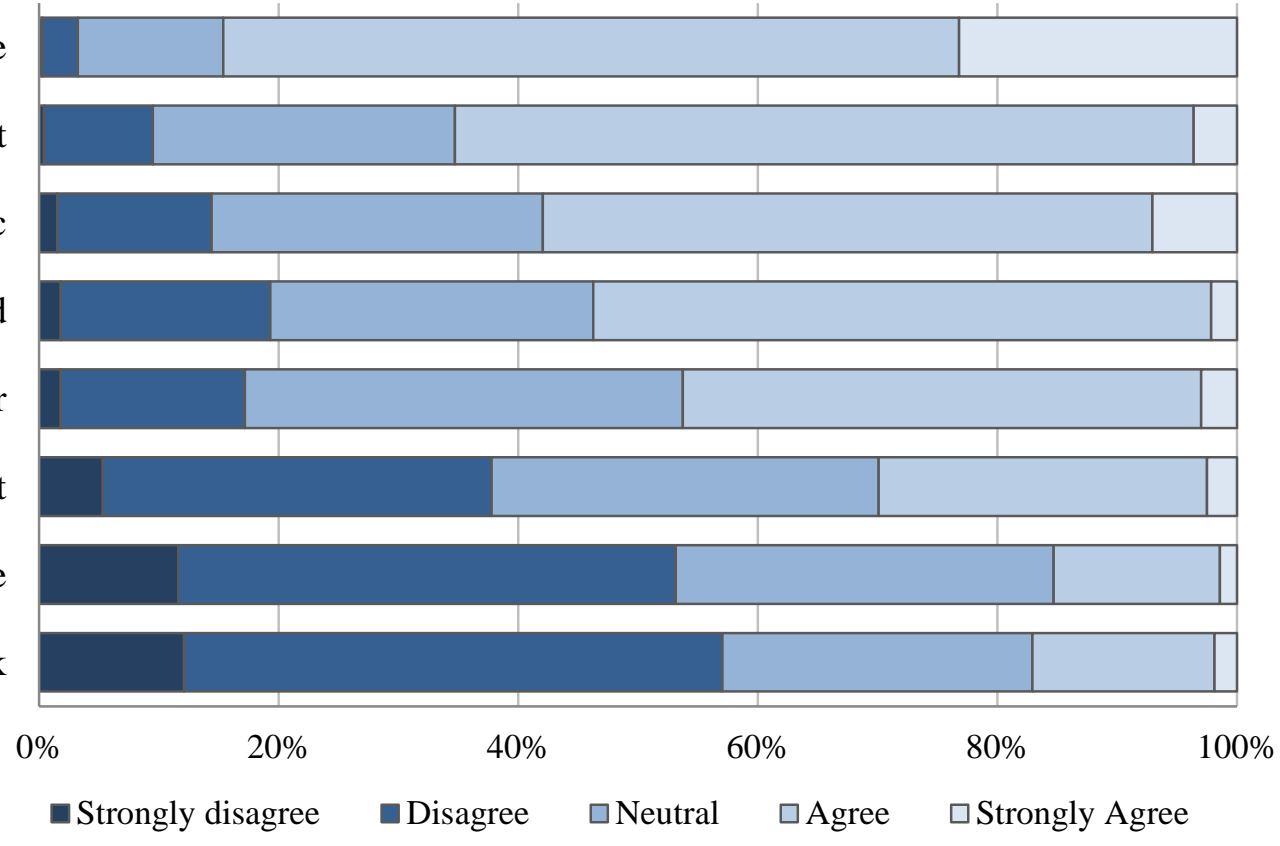
Running Head: PSYCHOLOGIST’S VIEWS ON PEER REVIEW

Figure 3: Response distributions for Perceived problems with peer reveiw, sorted by perceived prevalence $(\mathrm{N}=2,302)$. For original question ordering, see Table 3.

1. Review takes longer 6 months

7. Field leader bias

2. Rev lacks statistical understanding

3. Author/ editor close colleague

8. Rev lacks theoretical knowledge

4. Competing theory bias

9. Rev imposes (own) references

5. Bias against low ranked uni

6. Jr. reviewers withold criticism

10. Breach of confidentiality
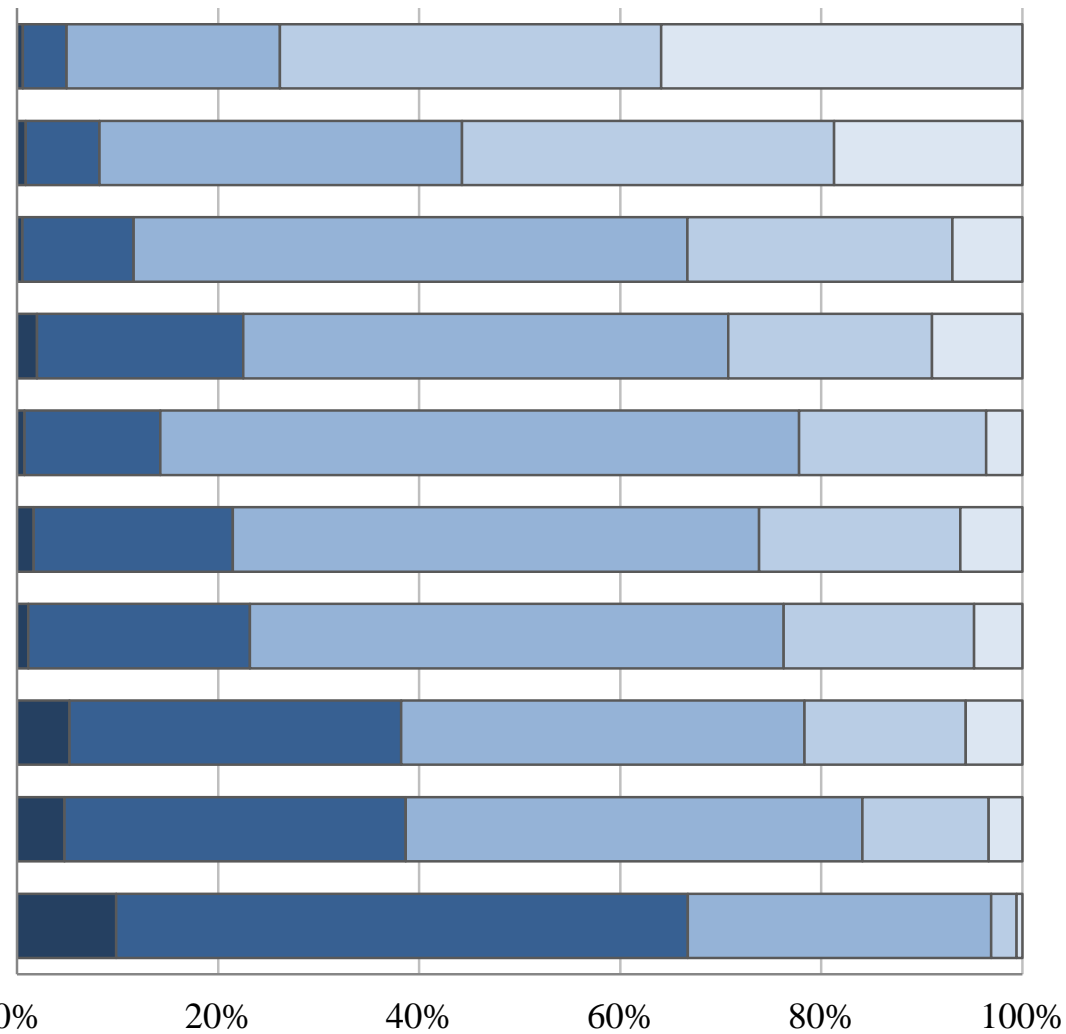

$\begin{array}{llllll}0 \% & 20 \% & 40 \% & 60 \% & 80 \% & 100 \%\end{array}$

aner $\square$ Hardly Ever $\square$ Sometimes $\square$ Frequently $\square$ Very Frequently 
PSYCHOLOGIST'S VIEWS ON PEER REVIEW

Figure 4: Displayed are the response distributions for potential solutions, ordered by perceived helpfulness $(\mathrm{N}=2,302)$. OriginalOriginal question ordering can be seen in Table 4.

9. Double-blind review

12. Journals screen QRPs

5. Incentivize good reviews

4. Include stats expert as rev.

1. Train reviewers

10. Use more checklists

11. Focus on quality (PLoS)

2. Establish appeals system

6. Tolerate imperfections

13. Post-publication review

15. Supplement $\mathrm{H}$-index

7. Lower competition to pub.

3. Publish peer review

14. Signed peer reviews

8. Single-blind review
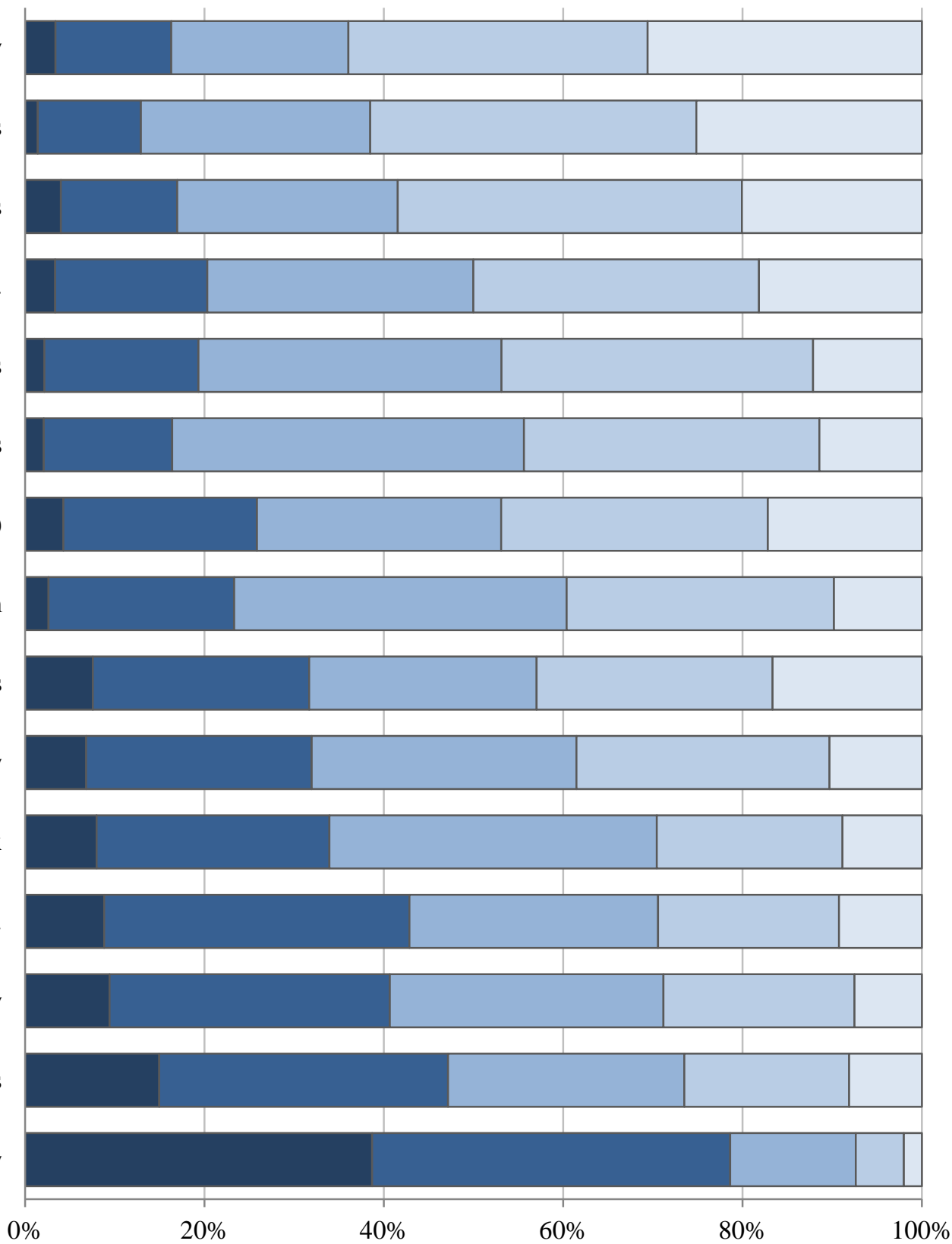

$\square$ Definitely not $\square$ Probably not $\square$ Maybe $\square$ Probably $\square$ Definitely 
Figure 5: Response distributions for Engagement in open science behaviors, ordered by engagement $(\mathrm{N}=2,302)$. The original question number is in indicated.

10. Use lab notebook

7. Conduct replications

9. Write up failed studies

2. Conduct secondary analysis

3. Use academic social media

4. Publish replications

5. Publish open access

1. Upload data to repository

8. Pre-register studies

6. Sign up for altmetrics
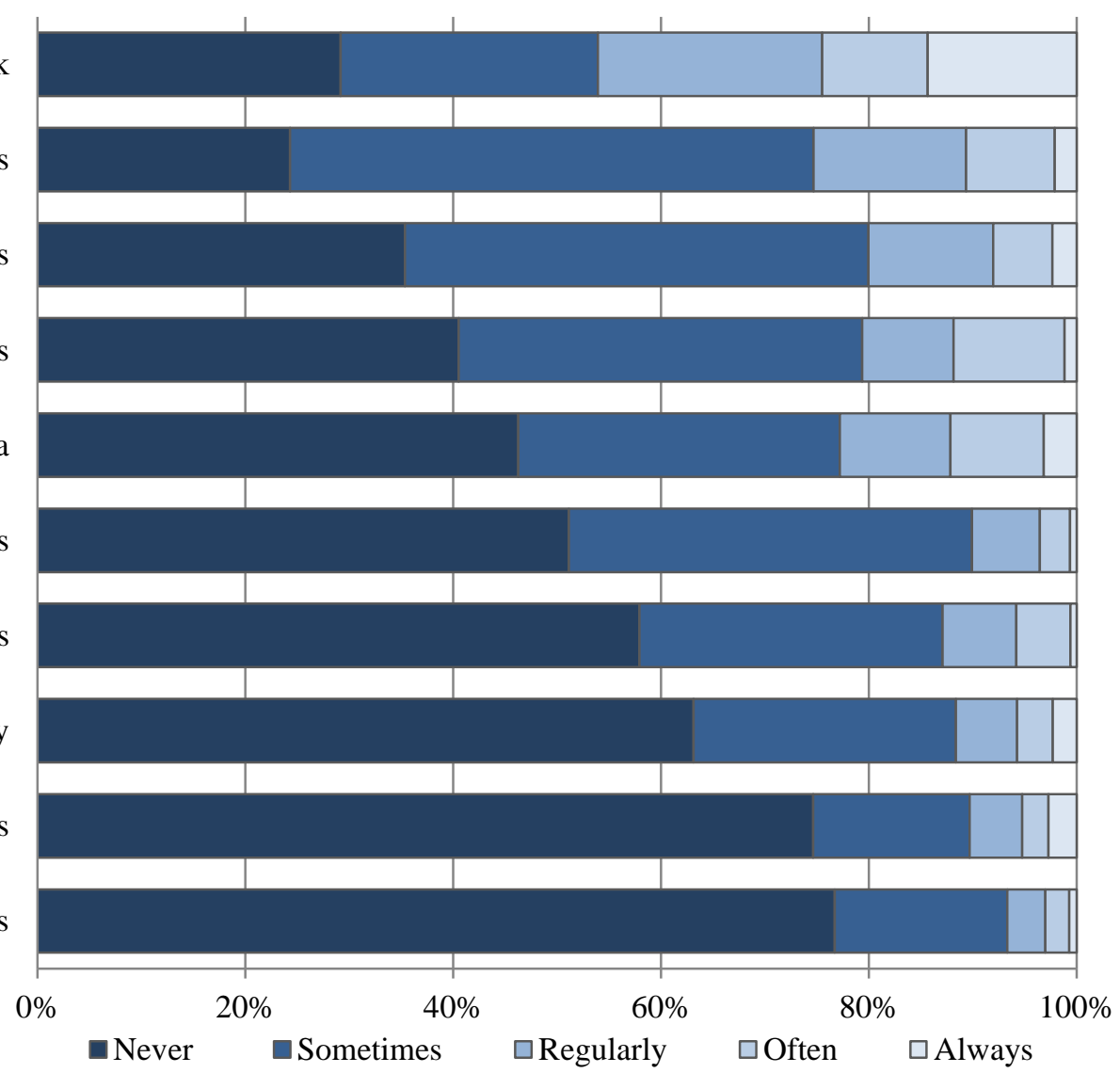
Figure 6: Differences in component scores based on subfield $(\mathrm{N}=2,302)$.

No Filedrawer

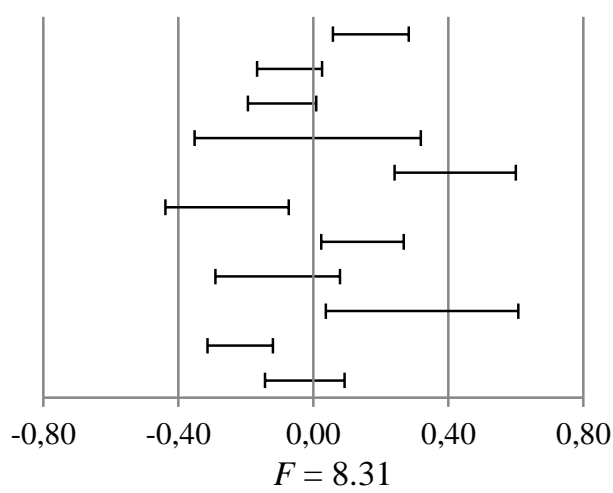

Trust in work

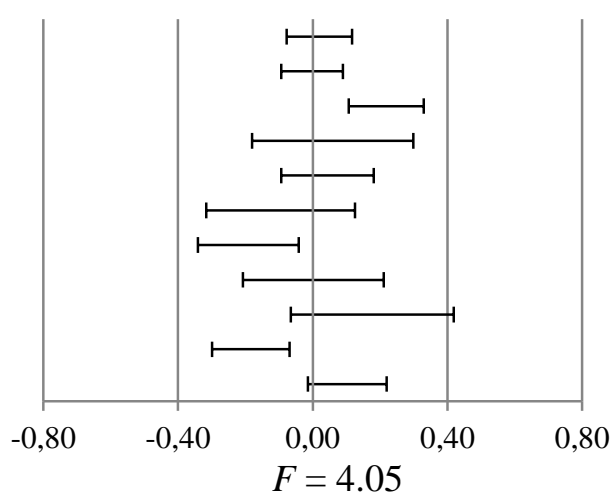

Lower competition

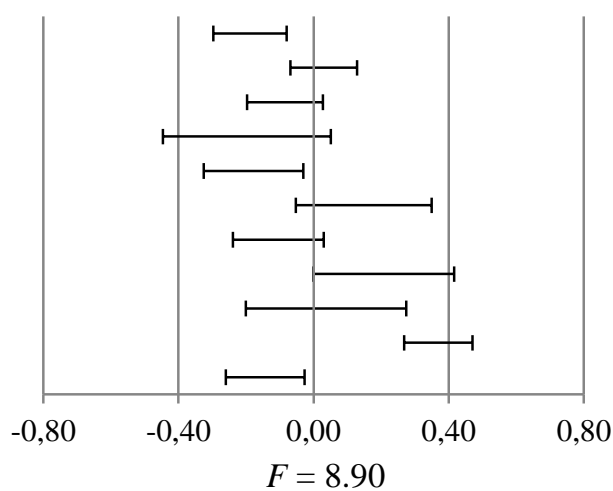

Social Media

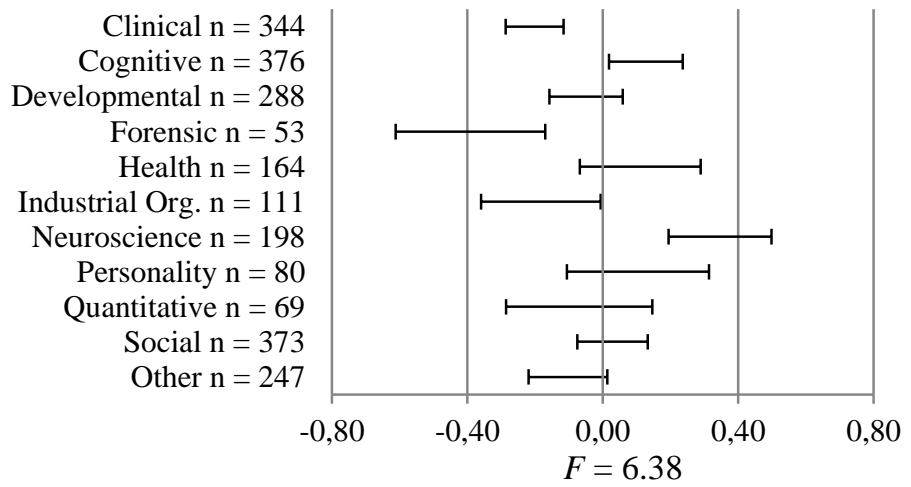

Bias

Clinical $n=344$

Cognitive $\mathrm{n}=376$

Developmental $\mathrm{n}=288$

Forensic $\mathrm{n}=53$

Health $\mathrm{n}=164$

Industrial Org. $\mathrm{n}=111$

Neuroscience $\mathrm{n}=198$

Personality $n=80$

Quantitative $\mathrm{n}=69$

Social $\mathrm{n}=373$

Other $n=247$

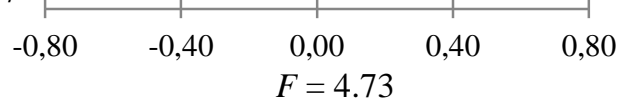

DoubleBlind

Clinical $n=344$

Cognitive $\mathrm{n}=376$

Developmental $n=288$

Forensic $\mathrm{n}=53$

Health $\mathrm{n}=164$

Industrial Org. $\mathrm{n}=111$

Neuroscience $\mathrm{n}=198$

Personality $n=80$

Quantitative $n=69$

Social $n=373$

Other $n=247$

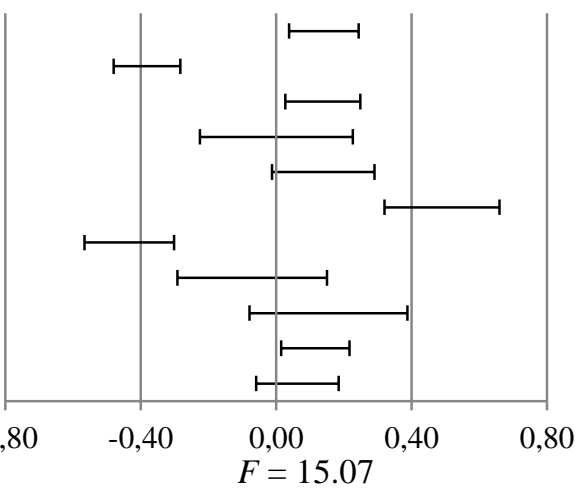

Note: All F tests are $F(10,2291)$. Significance of a group mean from the overall mean can be examined by seeing whether the grand mean $(0)$ is within the confidence interval of any specific group. 
Figure 7: Differences in component scores by number of publications $(\mathrm{N}=2,302)$.

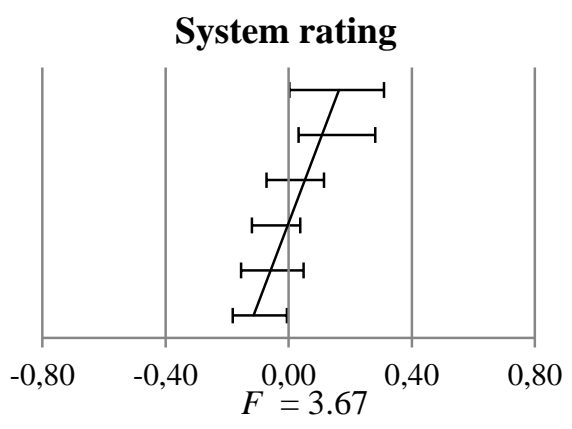

Open review system

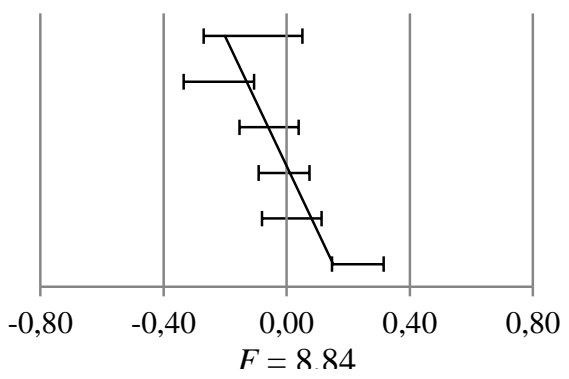

Strengthen Revs
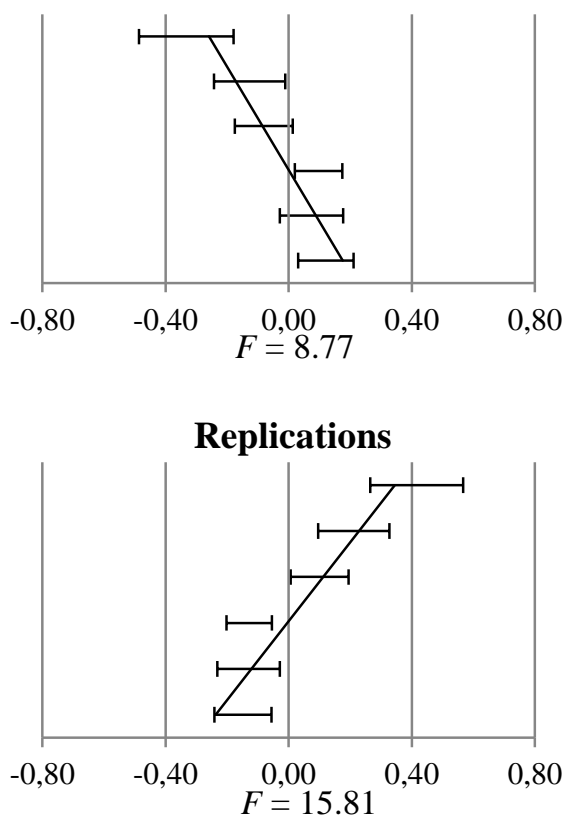

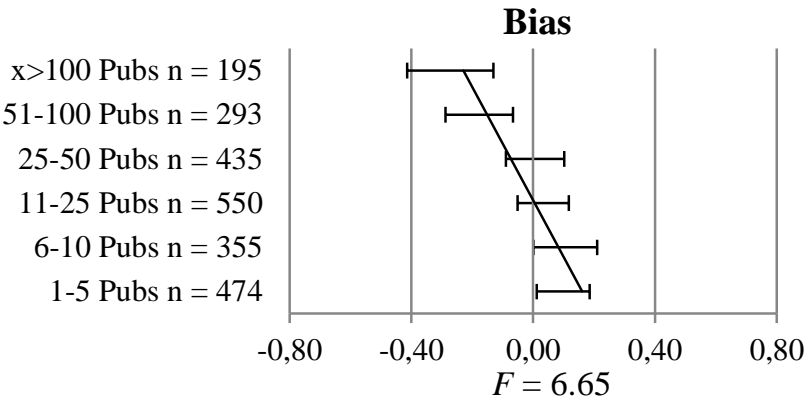

Lower competition
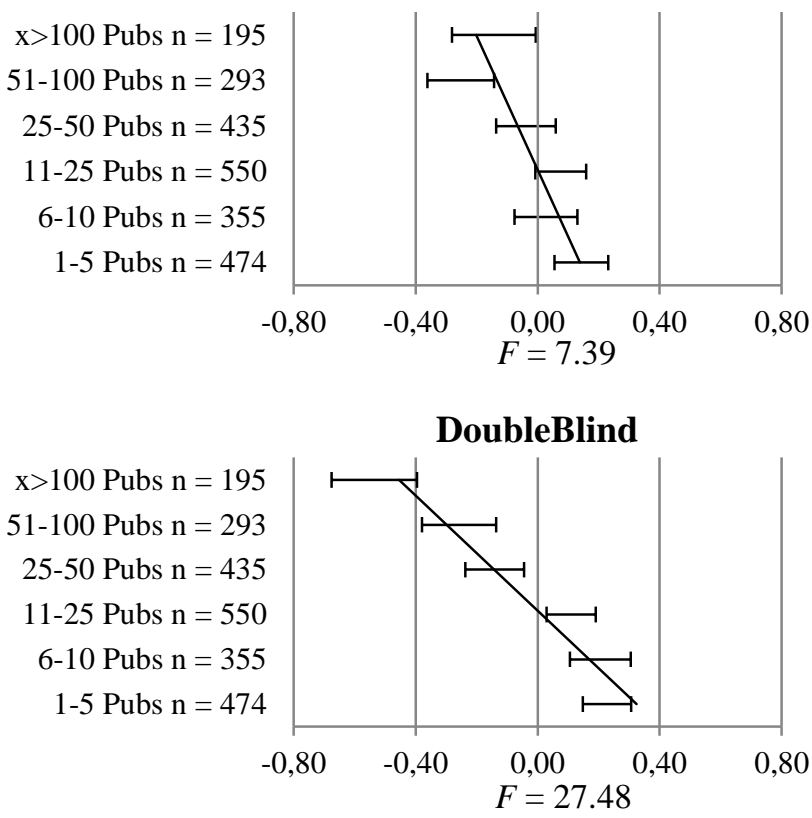

No Filedrawer

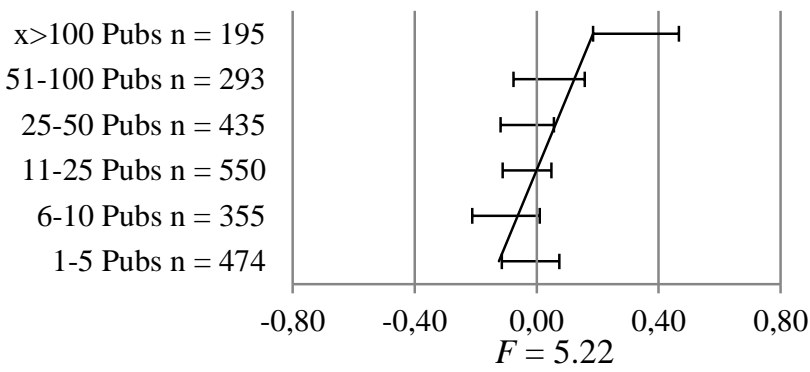

Note: Those individuals who had more publications: rated the system more highly, perceived less bias in the system, did not think lowering competition was a good solution, did not wish to strengthen reviews, did not like the double blind review system, did more replication, and put more energy into avoiding the file drawer. All $\mathrm{F}$ tests are $F(5,2296)$. Difference of a group mean from the overall mean can be examined by seeing whether the grand mean $(0)$ is within the confidence interval of any specific group. 


\section{Figure 8: Differences in component scores by number of reviews completed in the last year $(\mathrm{N}=2,302)$.}
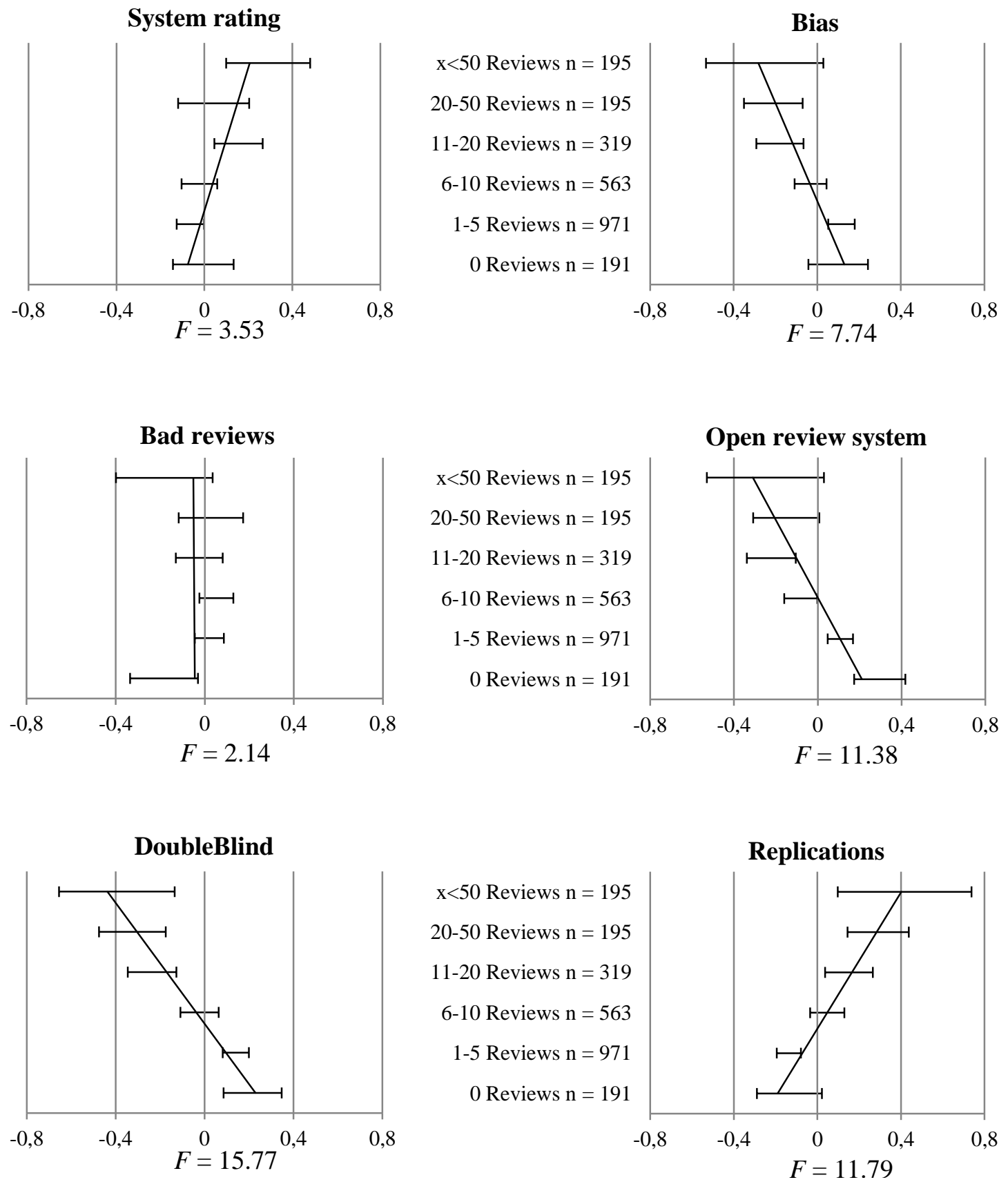

Note: Those individuals who had done more reviews in the last year: rated the system higher, perceived less bias in the system, disliked the double blind review system, did not want to open the review system, and did more replications. All $\mathrm{F}$ tests are $F(5,2296)$. Significance of a group mean from the overall mean can be examined by seeing whether the grand mean $(0)$ is within the confidence interval of any specific group. 